

\section{FROM THE DESK OF THE EDITOR}

Dear Colleagues:

Welcome to Issue 4 of Everyday Urology - Oncology Insights, our final issue for 2017. It's been a great year, and we certainly hope that you've found the breadth and quality of Everyday Urology's content to be insightful, timely and beneficial for optimally managing your clinical practice challenges.

This month, EvanYu, M.D. and Sumanta (Monty) Kumar Pal, M.D. will review and analyze the impact of current clinical trials on patient care, as described by the cover article, The Importance of Clinical Trials for Genitourinary Malignancies. Drs. Yu and Pal will address numerous and important key clinical questions embracing four main genitourinary malignancies: prostate, bladder/urothelial, renal and testicular germ cell cancers, explaining that if not for the dedication of researchers, investigators, and patients(trial subjects) who collectively dedicate their energies to clinical trials, we would not have the evidenced base information which results in regulatory approval and subsequent US and global access for life-prolonging therapies for the genitourinary cancers we diagnose and manage. Given that most trials do not achieve the desired clinical and statistically positive results aimed at regulatory approval, nonetheless, the knowledge gained will still often times advance clinical and scientific progress. As clinicians, we must embrace these goals and be continuously vigilant in promoting and educating patients regarding their need to participate in clinical research, as we are all physician-scientists at our core.

Also, within this issue of Everyday Urology are two outstanding articles presented as lectures during this past November in Chicago, IL at the Large Urology Group Practice Association (LUGPA) 2017 CME Session: Updates for Optimizing GU Oncology Cancer Clinics of Excellence Dr. Fred Saad and Dr. Charles Ryan discussed prostate cancer treatments and the issues involving sequencing of various therapies. Dr. Saad's presentation, Chemotherapy in Prostate Cancer:Why, When and How? provides perspective on the use of chemotherapy in patients with prostate cancer and the role that different therapies play throughout the progression of advanced prostate cancer. Dr. Saad sites data from multiple clinical trials, noting that almost all patients with $\mathrm{mCRPC}$ benefit from the use of hormonally-based therapy. Dr.
Saad also noted that for patients with metastatic PCa, chemotherapy plays an essential role upfront in specific patients. Urologists and Medical Oncologists dedicated to advanced prostate cancer care will enjoy his thorough and thoughtful review of the existing published trials and the possibilities for both specialties to administer chemotherapy as well via a multidisciplinary model. Assuredly, clinicians must recognize resistance patterns early so that patients can access the optimal number of approved lines of therapy or well suited clinical trials, thereby promoting precision and personalized medicine.

Dr. Charles Ryan carefully reviews the many sequences that exist in the treatment of prostate cancer, with his presentation, entitled, Sequencing and Combining CRPC Therapies: What Does the Future Hold? Dr. Ryan describes the CRPC patient population as a broad-spectrum of disease patterns, and thus the importance to recognize the principles of personalizing CRPC management. He reviews AR targeting in CRPC which provides the opportunity for clinical benefit with relatively low morbidity; however, resistance patterns will emerge via different routes of pathophysiology and thus are drivers of changes in tumor biology, requiring a nimbler approach toward therapeutic strategies. Dr. Ryan also discusses the role for tissue biopsies of metastases as well as "liquid biopsies" or ctDNA which will assuredly impact future clinical evaluation and treatment decision making.

Concluding this month's issue is extensive coverage from Société Internationale d'Urologie (SIU) Congress 2017 held in October in Lisbon, Portugal, where a number of compelling abstracts were presented from genitourinary experts worldwide including Martin Gleave's Optimal Sequencing and Monitoring of Androgen Receptor (AR) Pathway Inhibitors in $m C R P C$.

We greatly appreciate your support this year for Everyday Urology, and we look forward to bringing you the latest in hot topics, emerging treatments and expert options from our colleagues around the world in 2018.

Sincerely,

Neal Shore, MD, FACS

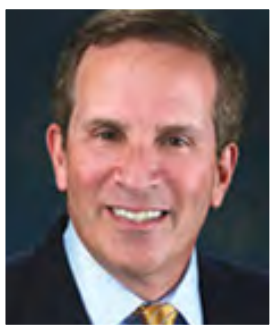

Neal Shore, MD, FACS is an internationally recognized expert in systemic therapies for patients with advanced urologic cancers and innovative therapies to treat patients suffering from prostate enlargement symptoms. Dr. Shore was recently appointed President-Elect of the Large Urology Group Practice Association (LUGPA), which seeks to provide urologists with all the tools they need to effectively care for patients. Neal D. Shore, MD, FACS, is the Medical Director of the Carolina Urologic Research Center. He practices with Atlantic Urology Clinics in Myrtle Beach, South Carolina. Dr. Shore has conducted more than 100 clinical trials, focusing mainly on prostate and bladder disease. 
Must-have resource

for urologjic professjonals

\section{SUNA}

Society of Urologic Nurses
and Associates

Core Curriculum
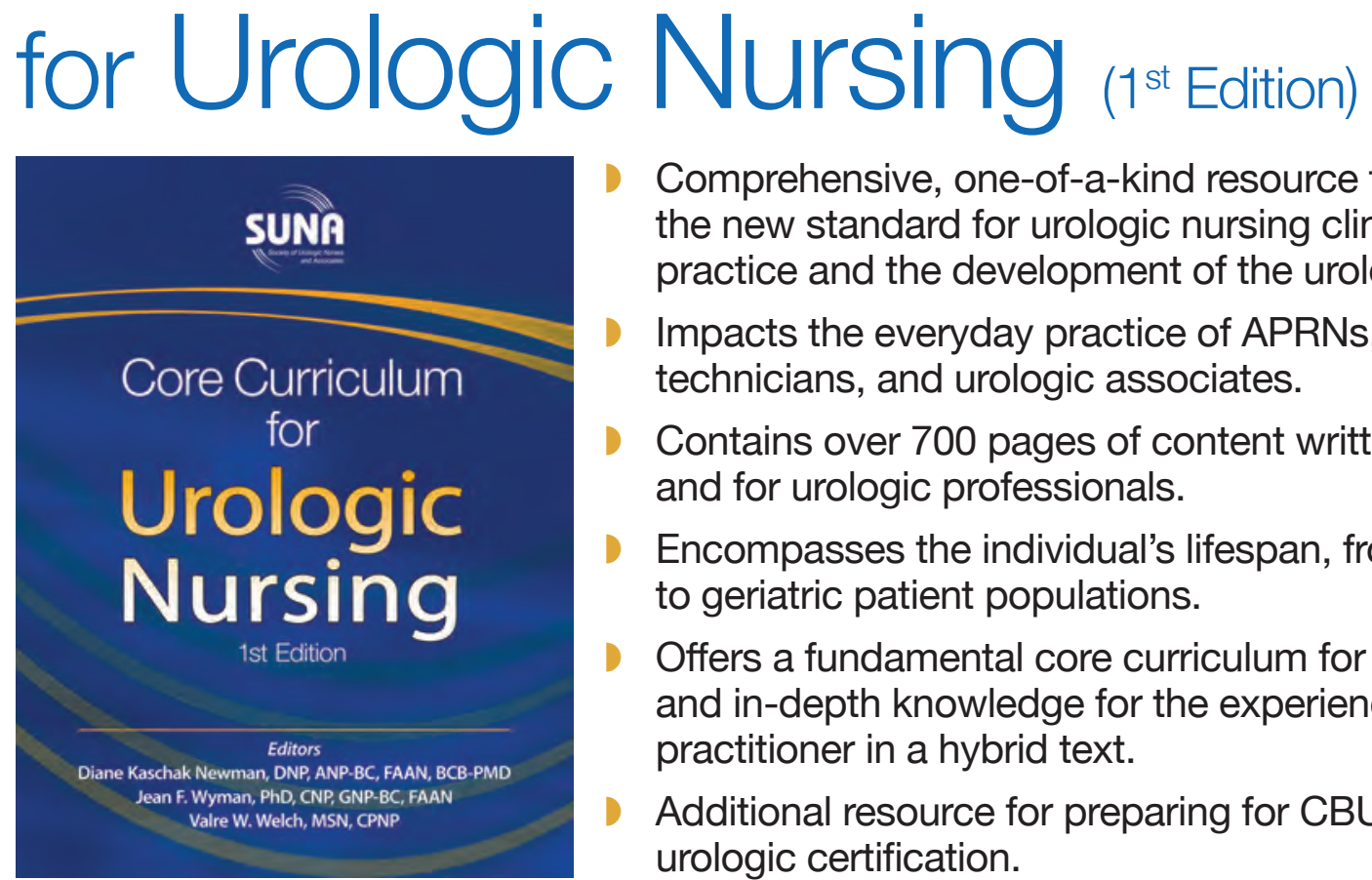

Comprehensive, one-of-a-kind resource that sets the new standard for urologic nursing clinical practice and the development of the urology APRN.

D Impacts the everyday practice of APRNs, RNs, PAs, technicians, and urologic associates.

D Contains over 700 pages of content written by and for urologic professionals.

D Encompasses the individual's lifespan, from pediatric to geriatric patient populations.

D Offers a fundamental core curriculum for the novice and in-depth knowledge for the experienced practitioner in a hybrid text.

Additional resource for preparing for CBUNA's urologic certification.

Section I Overview of Urologic Nursing

Section II Urologic Care of Infants and Children

NOW AVAILABLE

Section III Urologic Care of Adults: Assessment

Section IV Urologic Care of Adults: Genitourinary Cancers

Section V Urologic Care of Adults: Urologic Conditions

Member price: $\$ 149$ Regular price: $\$ 199$

Section VI Urologic Care of Women

Section VII Urologic Care of Men

Section VIII Adult Patient Undergoing Urologic Surgery

Order online at www.suna.org/core or call 888-827-7862

Section IX Special Adult Populations

Discounted bulk orders of the Core are available upon request. For additional information, please contact the SUNA National Office at 888-827-7862 / suna@ajj.com.

Special thanks for the support of our sponsors.
Platinum Sponsors

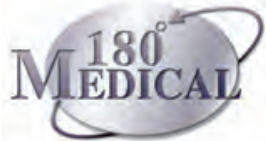

Silver Sponsor

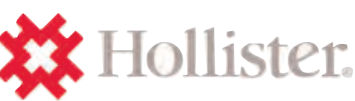

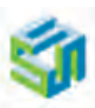

SAGENT 


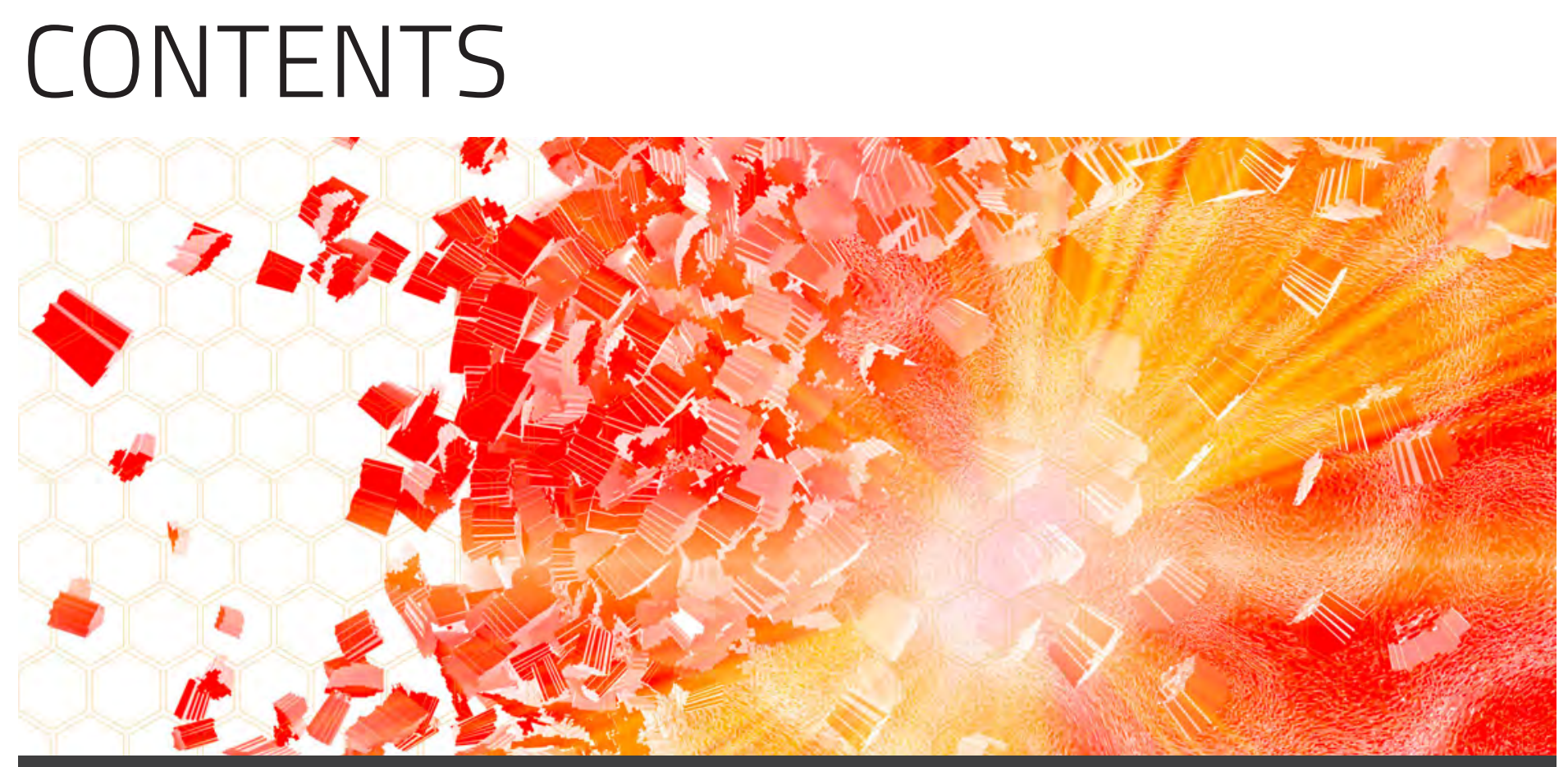

\section{COVER STORY}

14 The Importance of Clinical Trials for Genitourinary Malignancies

BY EVAN YU, MD, \& SUMANTA KUMAR PAL, MD

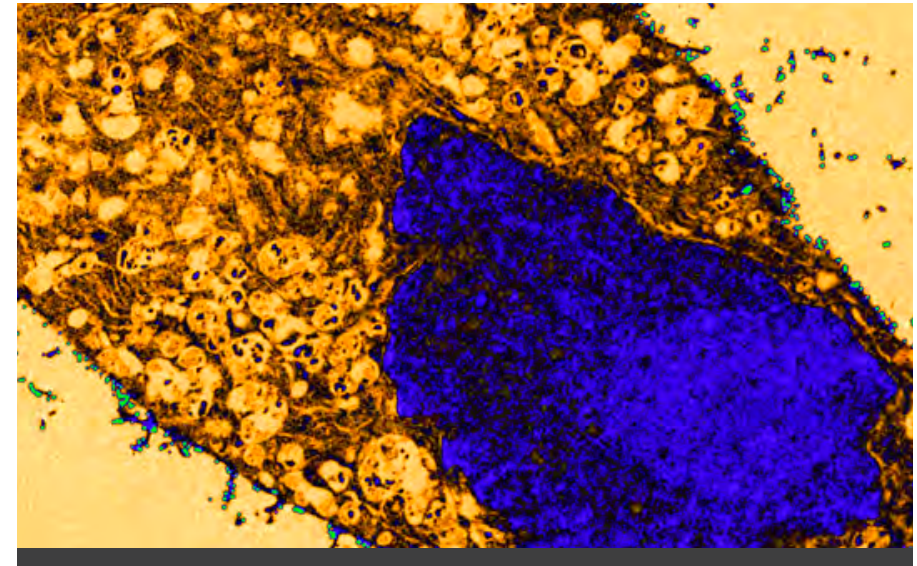

\section{EXPERT PERSPECTIVE}

20 Chemotherapy in Prostate Cancer: When, Why and How BY FRED SAAD, MD, FRCS

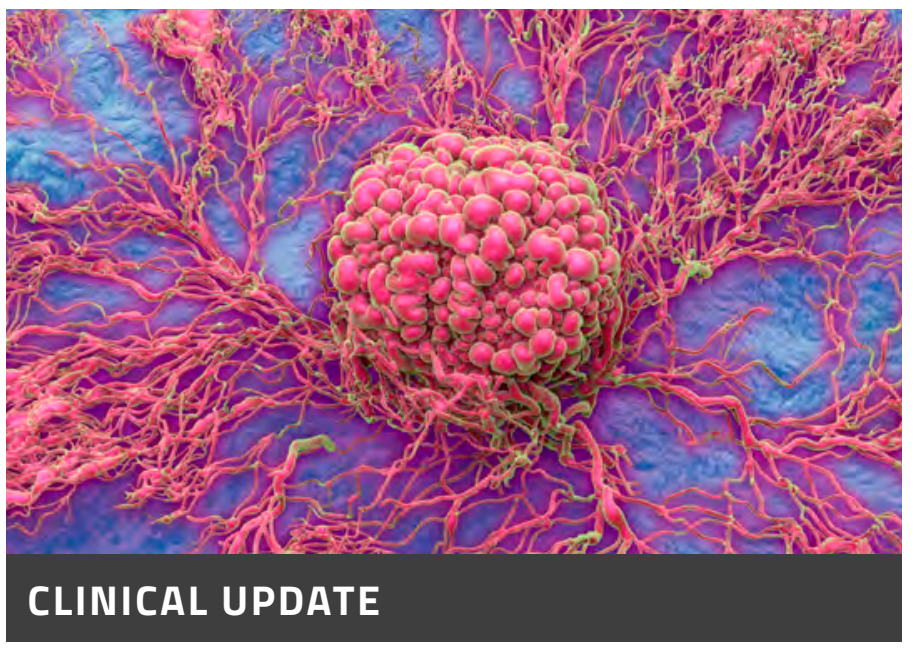

26 Sequencing and Combining CRPC Therapies: What Does the Future Hold? BY CHARLES J. RYAN, MD 


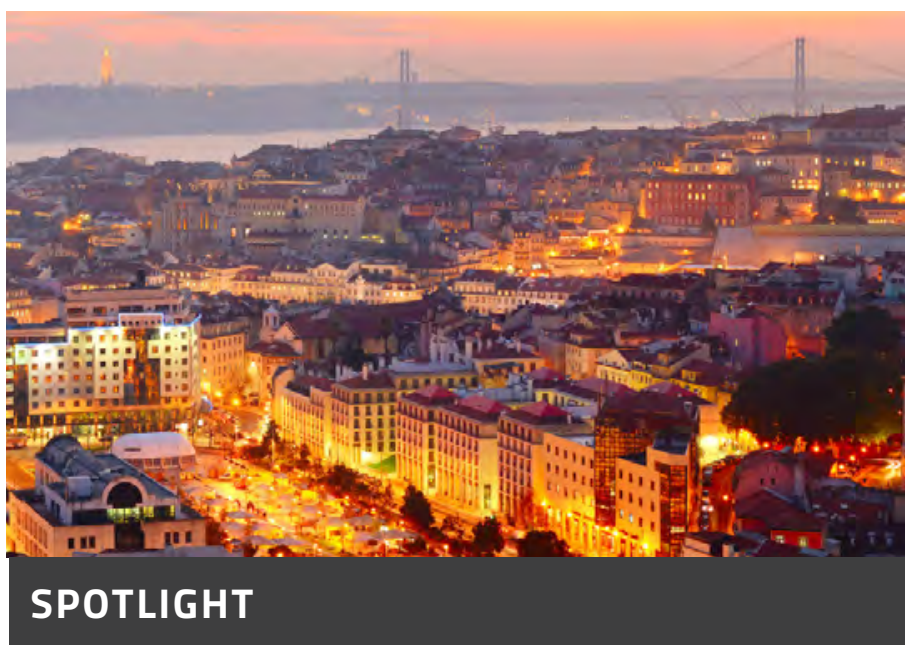

\section{Société Internationale d'Urologie 2017}

\section{Everyday Urology ${ }^{\circledR}$ ONCOLOGY INSIGHTS - A UROTODAY ${ }^{\circledR}$ PUBLICATION}

\section{Editorial Leadership}

EDITOR-IN-CHIEF

Neal Shore, MD, FACS

Atlantic Urology Clinics

Myrtle Beach, South Carolina

\section{Editorial Board}

Bishoy Morris Faltas, MD

Weill-Cornell Medical College

New York, New York

Petros Grivas, MD, PhD

Cleveland Clinic

Cleveland, Ohio

Ashish M. Kamat, MD, MBBS, FACS

The University of Texas, MD Anderson Cancer Center, Houston, Texas

Thomas Keane, MBBCh, FRCHI, FACS Medical University of South Carolina

Charleston, South Carolina

Badrinath Konety, MD, MBA

University of Minnesota

Minneapolis, Minnesota

\section{Digital Science Press Inc.}

\author{
Founder and CEO \\ Gina B. Carithers \\ Managing Editor \\ Courtney Leonard
}

President

Joseph Palumbo

Art Director

Lisa Holmes, Yulan Studio

DISCLAIMER: The statements and opinions contained in the articles of Everyday Urology ${ }^{\oplus}$ - Oncology Insights are solely those of the authors and contributors. The appearance of the advertisements in the publication is not a warranty, endorsement or approval of the products or services advertised or their effectiveness, quality or safety. The content of the publication may contain discussion of off-label uses of some of the agents mentioned. Please consult the prescribing information for full disclosure of approved uses. To the extent permissible under applicable laws, no responsibility is assumed by the publisher for any injury and/or damage as a result of any actual or alleged libelous statements, infringement of intellectual property, or privacy rights, or products liability whether resulting from negligence or otherwise, or for any use of operation, ideas, instructions, procedures, products, or methods contained within the material.

Everyday Urology ${ }^{\oplus}$ - Oncology Insights (ISSN 2473-3784) is published four times a year by Digital Science Press, Inc., business office located at 11448 Deerfield Drive, Suite 2, Truckee, CA. 96161.

POSTMASTER: Send address changes to Everyday Urology ${ }^{\circledR}$. Oncology Insights Digital Science Press, Inc. Subscription Customer Service, 11448 Deerfield Drive Suite 2, Truckee, CA 96161

CUSTOMER SERVICE: Customer service inquiries should be sent to publisher@urotoday.com Subscription inquiries should be sent to: cleonard@urotoday.com Access to this journal is online at www.urotoday.com Other correspondence for Digital Science Press, Inc. should be sent to: Attention: Digital Science Press, Inc. 11448 Deerfield Drive, Suite 2 Truckee, CA 96161 

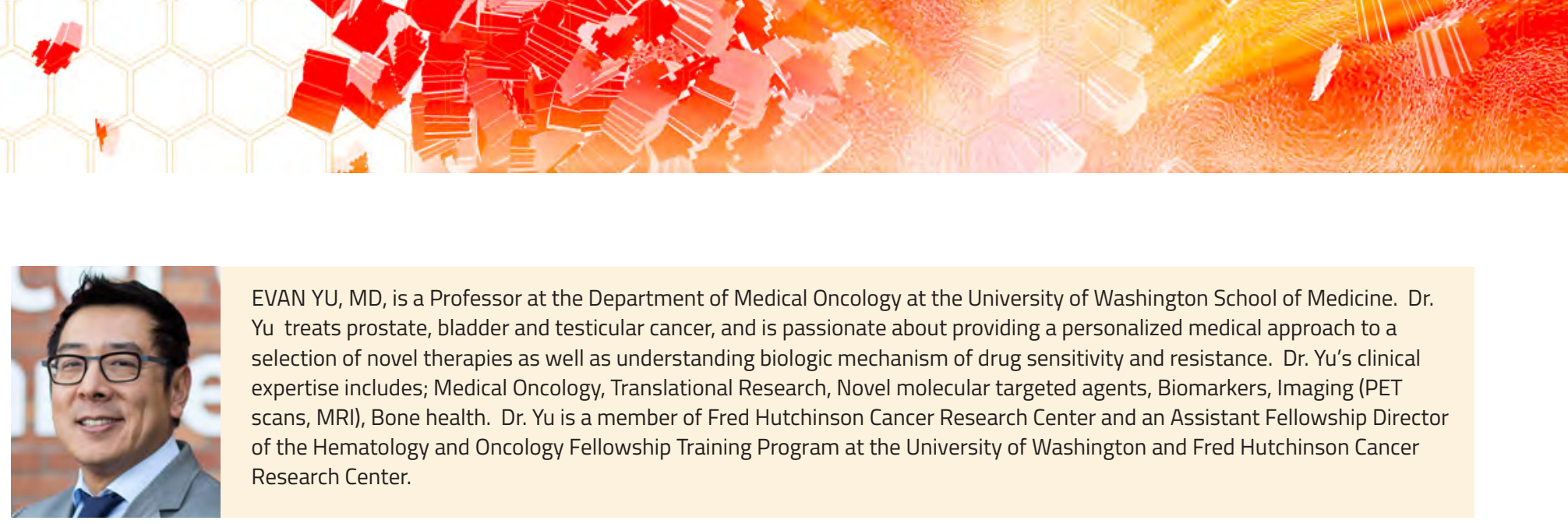

EVAN YU, MD, is a Professor at the Department of Medical Oncology at the University of Washington School of Medicine. Dr. Yu treats prostate, bladder and testicular cancer, and is passionate about providing a personalized medical approach to a selection of novel therapies as well as understanding biologic mechanism of drug sensitivity and resistance. Dr. Yu's clinical expertise includes; Medical Oncology, Translational Research, Novel molecular targeted agents, Biomarkers, Imaging (PET scans, MRI), Bone health. Dr. Yu is a member of Fred Hutchinson Cancer Research Center and an Assistant Fellowship Director of the Hematology and Oncology Fellowship Training Program at the University of Washington and Fred Hutchinson Cancer Research Center.

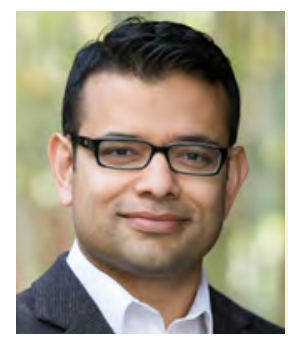

SUMANTA (MONTY) KUMAR PAL, MD, is an internationally recognized leader in the area of genitourinary cancers, including kidney, bladder, and prostatecancer. He is the Co-director of City of Hope's Kidney Cancer Program and is the head of the kidney and bladder cancer disease team at the institution. Dr. Pal holds patents for new drugs currently under development in prostate cancer and also maintains one of the largest portfolios of clinical trials for kidney and bladder cancer research on the west coast. He developed an integrated program that focuses heavily on collaborations with basic science researchers at Beckman Research Institute of City of Hope and urologists in the Department of Surgery.

\section{Clinical research is far from perfect. We unfortunately have more negative trials compared with positive trials. However, that should never deter us.}

A clinical research, there are two key messages to send. The first is that without clinical trials, we would not have access to the large number of life-prolonging therapies that we have for genitourinary cancers and others. That translates into more family trips, birthday parties, time spent with grandchildren and graduations attended. It translates into more time spent being productive at work, and net increase into societal wealth. These have meaningful impact. The second is that enrolling on a clinical trial is largely about altruism. The typical patient wants to receive a therapy that will help him/her. That is reasonable; however, the greatest reason to enroll on a clinical trial is that new knowledge will be gained regardless of the outcome. Of course, there is potential for a patient to receive clinical benefit, but regardless of the patient outcome, the scientific/medical community and future patients will benefit by learning not only what works but also what doesn't work. Additionally, a well-designed trial may also elucidate why something works or doesn't work. Hence, as a clinician, we need to view a part of our role is to educate patients about the favorable societal impact of participation in clinical research.

Unique to clinical research, the underlying goal is to improve how we treat or care for a real patient. To accomplish this, one must first recognize the clinical dilemmas that currently exist to be able to attack the problem. Hence, in this article, we propose to narrow down to what we view in our opinion are a couple key clinical questions that currently exist among the 4 main genitourinary malignancies, prostate, bladder/urothelial, renal and testicular germ cell cancers.

\section{PROSTATE CANCER}

There are numerous clinical questions for a disease like prostate cancer. This is largely due to the fortunate fact that the natural history of the disease is very long, making it very challenging to prove that any intervention is superior over any other or even no intervention. This is evident when considering the issues that

\section{Unique to clinical research, the underlying goal is to improve how we treat or care for a real patient. To accomplish this, one must first recognize the clinical dilemmas that currently exist to be able to attack the problem.}

surround early stages of prostate cancer such as prostate-specific antigen (PSA) screening, who to perform active surveillance on vs. local definitive therapy and the optimal local definitive treatment e.g. radical prostatectomy vs. external beam radiation therapy. However, it is reasonable to address some of the questions that affect people with more advanced stages of disease as outcome 


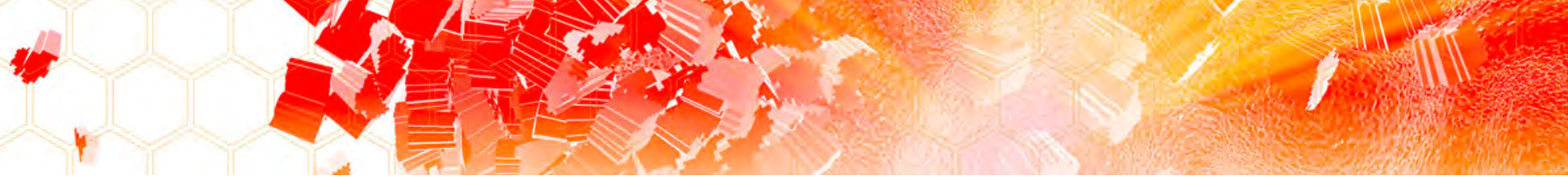

biologically relevant moieties outside of VEGF. These agents similarly had initial assessment in $\mathrm{mRCC}$ patients with prior exposure to VEGF-inhibitors. Cabozantinib, a VEGF-TKI with additional affinity for MET and AXL, demonstrated benefit in OS, $\mathrm{RR}$ and progression-free survival (PFS) relative to everolimus in the phase III METEOR trial. ${ }^{13}$ In a separate randomized phase II trial, the multikinase inhibitor lenvatinib, with affinity for fibroblast growth factor receptor (FGFR) as well as VEGF, was combined with everolimus. In comparison to everolimus monotherapy, the combination demonstrated an improvement in PFS and RR and a trend towards improved OS. ${ }^{14}$

Although hard to envision, these studies evaluating second-line therapy have become somewhat obsolete given two recently reported first-line trials. The first study, Checkmate214, is a randomized, phase III study including treatment-naïve patients with $\mathrm{mRCC}$. The study randomized patients to either nivolumab with ipilimumab or sunitinib, and demonstrated a significant benefit in OS and RR amongst patients with intermediate- and poor-risk disease. ${ }^{15}$ A second, smaller study, CABOSUN, compared cabozantinib to sunitinib and exclusively limited enrollment to patients with intermediate- and poor-risk disease. In this randomized, phase II study, a significant improvement in $\mathrm{RR}$ and PFS was observed, with a trend towards benefit in OS. ${ }^{16}$ While these two studies offer reasonable front-line options for advanced disease, there are a wealth of front-line clinical trials that have yet to report out which may add further to this armamentarium.

- Lenvatinib/Everolimus or Lenvatinib/Pembrolizumab Versus Sunitinib Alone as Treatment of Advanced Renal Cell Carcinoma (NCT0281 1861)

- A Study of Atezolizumab in Combination With Bevacizumab Versus Sunitinib in Participants With Untreated Advanced Renal Cell Carcinoma [IMmotion151] (NCT02420821)

\section{- A Study of Avelumab With Axitinib Versus Sunitinib In Advanced Renal Cell Cancer (JAVELIN Renal 101) (NCT02684006)}

- Study to Evaluate the Efficacy and Safety of Pembrolizumab (MK-3475) in Combination With Axitinib Versus Sunitinib Monotherapy in Participants With Renal Cell Carcinoma (MK3475-426/KEYNOTE-426) (NCT02853331)

Beyond advance disease, there is renewed interest in the setting of localized disease. Two studies evaluating adjuvant VEGF-TKIs, PROTECT and ASSURE, have produced resoundingly negative results. PROTECT compared pazopanib to placebo, while ASSURE compared sunitinib monotherapy and sorafenib monotherapy to placebo. ${ }^{17,18}$ A third trial, S-TRAC, showed a modest gain in disease-free survival (DFS) with sunitinib versus placebo in the adjuvant setting, but despite an associated FDA approval, it is anticipated that utilization of this regimen will be low on account of toxicities associated with the agent. Furthermore, the study has shown no evidence of OS benefit to date. ${ }^{19}$ Four trials evaluating adjuvant checkpoint inhibition will hopefully skew the risk/benefit ratio in a more positive direction. These studies are as follows:

- A Study of Atezolizumab as Adjuvant Therapy in Participants With Renal Cell Carcinoma (RCC) at High Risk of Developing Metastasis Following Nephrectomy (IMmotion010) (NCT03024996)

- Safety and Efficacy Study of Pembrolizumab (MK-3475) as Monotherapy in the Adjuvant Treatment of Renal Cell Carcinoma Post Nephrectomy (MK-3475-564/KEYNOTE-564) (NCT03142334)

- A Study Comparing the Combination of Nivolumab and Ipilimumab Versus Placebo in Participants With Localized Renal Cell Carcinoma (CheckMate 914) (NCT03138512)

- Nivolumab in Treating Patients With Localized Kidney Cancer Undergoing Nephrectomy (PROSPER) NCT03055013

\section{BLADDER CANCER}

In advanced bladder cancer, cisplatin-based chemotherapy has long been cornerstone of treatment. Within the past several years, just as in $\mathrm{mRCC}$, checkpoint inhibition has become incorporated into the treatment paradigm. For patients with prior platinum-based chemotherapy (either for metastatic disease or in the perioperative setting), two phase III trials have shown clinical benefit relative to standard chemotherapy. In KEYNOTE-045,

In advanced bladder cancer, cisplatin-based chemotherapy has long been cornerstone of treatment. Within the past several years, just as in $\mathrm{mRCC}$, checkpoint inhibition has become incorporated into the treatment paradigm.

patients were randomized to receive either pembrolizumab or cytotoxic chemotherapy until the time of progression or intolerable toxicity. Possible chemotherapy regimens included paclitaxel, docetaxel and vinflunine. Pembrolizumab led to an improvement in both RR and OS. ${ }^{20} \mathrm{~A}$ second trial, Imvigor-2 11 , had an almost equivalent study design, examining atezolizumab as opposed to pembrolizumab. Although the study failed to meet its primary endpoint (an improvement in OS in a PD-Ll-enriched population), there was a strong trend towards OS in the overall study population. Furthermore, atezolizumab appeared to clearly show benefit in OS as compared to regimens such as docetaxel and paclitaxel, most salient to U.S.-based practices. ${ }^{21}$

Three other single arm phase II studies have explored the benefit of checkpoint inhibition in patients with prior platinum-based therapies. These studies, assessing nivolumab ${ }^{22}$, durvalumab ${ }^{23}$ and avelumab ${ }^{24}$, have each shown largely similar $\mathrm{RR}$ and PFS data. 
A clinical conundrum has been the management of patients with cisplatin-ineligible disease. A variety of carboplatin-based regimens have been attempted in this setting, and guidelines still incorporate carboplatin-gemcitabine as a reasonable choice in this setting, despite relatively poor PFS and OS associated with this doublet regimen. Two phase II studies have led to approvals for pembrolizumab and atezolizumab in this setting. Both studies show RRs above $20 \%$ and OS exceeding 1 year, therefore constituting a major development in this poor-prognosis subset of patients. ${ }^{25,26}$

Moving forward in the front-line setting, several trials will take the bold step of combining chemotherapy with checkpoint inhibition or the even bolder step of juxtaposing immunotherapy alone against chemotherapy:

- Study of Atezolizumab as Monotherapy and in Combination

With Platinum-Based Chemotherapy in Participants With

Untreated Locally Advanced or Metastatic Urothelial Carcinoma (IMvigor 130) NCT02807636

- Study of Nivolumab in Combination With Ipilimumab or Standard of Care Chemotherapy Compared to the Standard of Care Chemotherapy Alone in Treatment of Patients With Untreated Inoperable or Metastatic Urothelial Cancer (CheckMate901) NCT03036098

- Study of MEDI4736 (Durvalumab) With or Without Tremelimumab Versus Standard of Care Chemotherapy in Urothelial Cancer NCT02516241

- Study of Pembrolizumab With or Without Platinum-based Combination Chemotherapy Versus Chemotherapy Alone in Urothelial Carcinoma (MK-3475-361/KEYNOTE-361) NCT02853305:

There are also efforts to move systemic therapy to the setting of muscle-invasive and non-muscle invasive setting. Studies of adjuvant nivolumab and atezolizumab are well underway, and a cooperative-group sponsored study assessing adjuvant pembrolizumab has just launched:

- A Study of Atezolizumab Versus Observation as Adjuvant Therapy in Participants With High-Risk Muscle-Invasive Urothelial Carcinoma (UC) After Surgical Resection (IMvigor010) NCT02450331

- Pembrolizumab in Treating Patients With Locally Advanced Bladder Cancer NCT03244384

- An Investigational Immuno-therapy Study of Nivolumab, Compared to Placebo, in Patients With Bladder or Upper Urinary Tract Cancer, Following Surgery to Remove the Cancer (CheckMate 274) NCT02632409

\section{TESTICULAR CANCER}

Testicular germ cell cancer is fortunately a disease where we have outstanding long-term outcomes. Hence, there is little ongoing clinical research. However, there are a couple of disease states where outcomes could be significantly improved with advancements in the field, and more clinical trials in these settings are needed.

For patients with refractory or relapsed germ cell tumor after initial cisplatin-based combination chemotherapy, it is yet uncertain how to achieve optimal outcomes. The debate centers around whether a patient should receive a salvage combination cisplatin

For patients with refractory or relapsed

germ cell tumor after initial cisplatin-based

combination chemotherapy, it is yet uncertain

how to achieve optimal outcomes.

chemotherapy regimen or whether high dose chemotherapy with autologous stem cell rescue ${ }^{27}$ should be introduced. Traditionally, transplant has been utilized in the $3^{\text {rd }}$ line and attempts at introduction in the $1^{\text {st }}$ line have not shown improved outcomes. ${ }^{28}$ The Alliance Cooperative Group in the United States is performing a large randomized trial in this setting testing standard dose TI-CE salvage chemotherapy vs. TI with high dose chemotherapy with stem cell transplant for patients in the $2^{\text {nd }}$ line.

- Standard dose salvage chemotherapy vs. high dose chemotherapy with stem cell transplant (NCT02375204)

The other major clinical dilemma is how best to improve outcomes for patients who have relapsed after stem cell transplant, where there are no remaining curative treatment options. This is a disease state where many more clinical trials need to be developed. There are currently a couple ongoing trials exploring Brentuximab vedotin as embryonal carcinoma expresses CD30. There have also been isolated case reports of the activity of checkpoint inhibitors for patients with resistant germ cell tumors, ${ }^{29,30}$ and as a result, there is an ongoing prospective trial testing combination checkpoint inhibitors. Some trials available for advanced, refractory/relapsed germ cell tumors are listed below:

- Brentuximab Vedotin in Relapsed/Refractory Germ Cell Tumors (NCT02689219)

- Study of Brentuximab Vedotin And Bevacizumab In Refractory CD-30 Positive Germ Cell Tumors (NCT02988843)

- Evaluating Immune Therapy, Duravalumab (MEDI4736) With Tremelimumab for Relapsed/Refractory Germ Cell Tumors (NCT03158064)

\section{CONCLUSIONS/FUTURE DIRECTIONS}

For each genitourinary cancer subtype (prostate, bladder, kidney and testicular), management strategies for both localized 


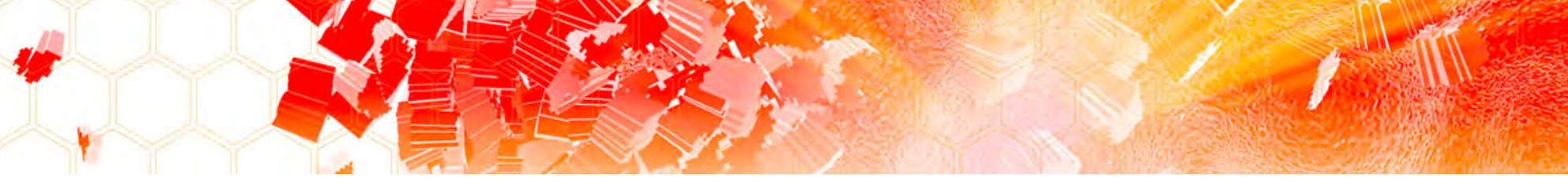

and advanced disease vary widely. However, as we review current clinical trial strategies, several themes emerge. First, there is an effort to interrogate the role of immunotherapy across each of these malignancies. At first glance, this may be somewhat surprising. Checkpoint inhibition has typically exerted the most potent effect in tumor types bearing a high mutational burden. With the exception of bladder cancer, genitourinary tumors tend to either demonstrate low or moderate mutational burden. In diseases such as prostate cancer or testicular cancer, it may be the rare patient with microsatellite instability that demonstrates a response to therapy, or a combination of therapies (e.g., PARP inhibition with checkpoint inhibition in prostate cancer) may be necessary to drive response. In diseases such as renal cell carcinoma, factors outside of mutational burden (for instance, the frequency of frameshift mutations) have been recently suggested to predict response to therapy.

Another pervasive theme across these studies is that many seek to add novel therapies to existing treatment modalities. In testicular cancer and bladder cancer, for instance, studies of checkpoint inhibition utilize a chemotherapy backbone. In prostate cancer, several combinations of already approved therapies (e.g., radium-223, enzalutamide or docetaxel) serve as the backbone of trials of PARP inhibitors. This is a pragmatic approach that may ultimately help resolve dilemmas in treatment sequencing.

Finally, it should be encouraging to see a trend towards exploring novel systemic therapies in earlier settings. In bladder and kidney cancer, studies of checkpoint inhibitors are now steadily accruing in patients with resected localized disease.

\section{Finally, it should be encouraging to see a trend towards exploring novel systemic therapies in earlier settings.}

In prostate cancer, treatment strategies previously reserved for advanced disease are now moving into patients with high-risk localized disease and biochemical recurrence. As a field, we should continue to strive for better outcomes through clinical research by importing highly efficacious therapies earlier in the treatment paradigm.

\section{REFERENCES}

1. Robinson $D$, Van Allen EM, Wu YM, et al: Integrative clinical genomics of advanced prostate cancer. Cell 161:1215-1228, 2015

2. Pritchard CC, Mateo J, Walsh MF, et al: Inherited DNA-Repair Gene Mutations in Men with Metastatic Prostate Cancer. N Engl J Med 375:443-53, 2016

3. Sweeney CJ, Chen Y-H, Carducci M, et al: Chemohormonal Therapy in Metastatic Hormone-Sensitive Prostate Cancer. New England Journal of Medicine 373:737-746, 2015

4. James ND, Sydes MR, Clarke NW, et al: Addition of docetaxel, zoledronic acid, or both to first-line longterm hormone therapy in prostate cancer (STAMPEDE): survival results from an adaptive, multiarm, multistage, platform randomised controlled trial. Lancet 387:1163-77, 2016

5. Ryan CJ, Smith MR, Fizazi K, et al: Abiraterone acetate plus prednisone versus placebo plus prednisone in chemotherapy-naive men with metastatic castration-resistant prostate cancer (COU-AA-302): final overall survival analysis of a randomised, double-blind, placebo-controlled phase 3 study. Lancet Oncol 16:152-60, 2015

6. James ND, de Bono JS, Spears MR, et al: Abiraterone for Prostate Cancer Not Previously Treated with Hormone Therapy. New England Journal of Medicine 377:338-351, 2017

7. Crook JM, O'Callaghan CJ, Duncan G, et al: Intermittent Androgen Suppression for Rising PSA Level after Radiotherapy. New England Journal of Medicine 367:895-903, 2012

8. Pound CR, Partin AW, Eisenberger MA, et al: Natural history of progression after PSA elevation following radical prostatectomy. JAMA 281:1591-7, 1999

9. Zagars GK, Pollack A: Kinetics of serum prostate-specific antigen after external beam radiation for clinically localized prostate cancer. Radiother Oncol 44:213-21, 1997

10. D'Amico AV, Moul J, Carroll PR, et al: Prostate specific antigen doubling time as a surrogate end point for prostate cancer specific mortality following radical prostatectomy or radiation therapy. J Uro 172:S42-6; discussion S46-7, 2004

11. Choueiri TK, Motzer RJ: Systemic Therapy for Metastatic Renal-Cell Carcinoma. New England Journal of Medicine 376:354-366, 2017

12. Escudier B, Sharma P, McDermott DF, et al: CheckMate 025 Randomized Phase 3 Study: Outcomes by Key Baseline Factors and Prior Therapy for Nivolumab Versus Everolimus in Advanced Renal Cell Carcinoma. Eur Urol 72:962-971, 2017

13. Choueiri TK, Escudier B, Powles T, et al: Cabozantinib versus everolimus in advanced renal cell carcinoma (METEOR): final results from a randomised, open-label, phase 3 trial. Lancet Oncol 17:917927,2016

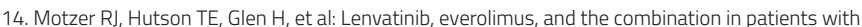
metastatic renal cell carcinoma: a randomised, phase 2 , open-label, multicentre trial. Lancet Onco $16: 1473-82,2015$

15. Hammers HJ, Plimack ER, Sternberg C, et al: CheckMate 214: A phase III, randomized, open-label study of nivolumab combined with ipilimumab versus sunitinib monotherapy in patients with previously untreated metastatic renal cell carcinoma. Journal of Clinical Oncology 33:TPS4578-TPS4578, 2015

16. Choueiri TK, Halabi S, Sanford BL, et al: Cabozantinib Versus Sunitinib As Initial Targeted Therapy for Patients With Metastatic Renal Cell Carcinoma of Poor or Intermediate Risk: The Alliance A031203 CABOSUN Trial. J Clin Oncol 35:591-597, 2017

17. Motzer RJ, Haas NB, Donskov F, et al: Randomized Phase III Trial of Adjuvant Pazopanib Versus Placebo After Nephrectomy in Patients With Localized or Locally Advanced Renal Cell Carcinoma. J Clin Oncol:JCO2017735324, 2017

18. Haas NB, Manola J, Uzzo RG, et al: Adjuvant sunitinib or sorafenib for high-risk, non-metastatic renal-cell carcinoma (ECOG-ACRIN E2805): a double-blind, placebo-controlled, randomised, phase 3 trial. Lancet 387:2008-16, 2016

19. Ravaud A, Motzer RJ, Pandha HS, et al: Adjuvant Sunitinib in High-Risk Renal-Cell Carcinoma after Nephrectomy. N Engl J Med 375:2246-2254, 2016

20. Bellmunt J, de Wit R, Vaughn DJ, et al: Pembrolizumab as Second-Line Therapy for Advanced Urothelial Carcinoma. N Engl J Med 376:1015-1026, 2017

21. Hoffman-Censits JH, Grivas P, Heijden MSVD, et al: IMvigor 210, a phase II trial of atezolizumab (MPDL $3280 A$ ) in platinum-treated locally advanced or metastatic urothelial carcinoma (mUC). Journal of Clinical Oncology 34:355-355, 2016

22. Sharma P, Retz M, Siefker-Radtke A, et al: Nivolumab in metastatic urothelial carcinoma after platinum therapy (CheckMate 275): a multicentre, single-arm, phase 2 trial. The Lancet Oncology 18:312-322

23. Massard C, Gordon MS, Sharma S, et al: Safety and Efficacy of Durvalumab (MEDI4736), an AntiProgrammed Cell Death Ligand-1 Immune Checkpoint Inhibitor in Patients With Advanced Urothelia Bladder Cancer. Journal of Clinical Oncology 34:3119-3125, 2016

24. Apolo AB, Infante JR, Balmanoukian A, et al: Avelumab, an Anti-Programmed Death-Ligand 1 Antibody, In Patients With Refractory Metastatic Urothelial Carcinoma: Results From a Multicenter Phase Ib Study. Journal of Clinical Oncology 35:2117-2124, 2017

25. Balar AV, Castellano D, O'Donnell PH, et al: First-line pembrolizumab in cisplatin-ineligible patients with locally advanced and unresectable or metastatic urothelial cancer (KEYNOTE-052): a multicentre single-arm, phase 2 study. The Lancet Oncology 18:1483-1492, 2017

26. Rosenberg JE, Hoffman-Censits J, Powles T, et al: Atezolizumab in patients with locally advanced and metastatic urothelial carcinoma who have progressed following treatment with platinum-based chemotherapy: a single-arm, multicentre, phase 2 trial. The Lancet 387:1909-1920

27. Einhorn LH, Williams SD, Chamness A, et al: High-Dose Chemotherapy and Stem-Cell Rescue for Metastatic Germ-Cell Tumors. New England Journal of Medicine 357:340-348, 2007

28. Motzer RJ, Nichols CJ, Margolin KA, et al: Phase III Randomized Trial of Conventional-Dose Chemotherapy With or Without High-Dose Chemotherapy and Autologous Hematopoietic Stem-Cell Rescue As First-Line Treatment for Patients With Poor-Prognosis Metastatic Germ Cell Tumors. Journa of Clinical Oncology 25:247-256, 2007

29. Schabitz S et al. Eur J Cancer 2017; 76:1-7.

30. Chi EA et al. Clin Genitourin Cancer 2017; Epub April 12 



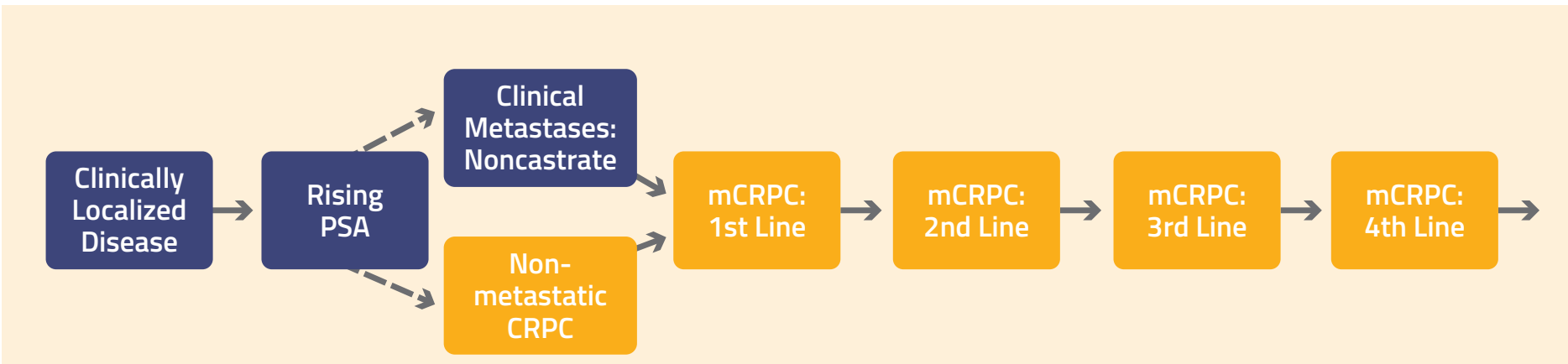

Noncastrate

Castration-resistant

Figure 1: Prostate Cancer Clinical States Model as Updated by the Prostate Cancer Clinical Trials Working Group 3 (PCWG3) Guidelines. $C R P C=$ castration-resistant prostate cancer; $m C R P C=$ metastatic castration-resistant prostate cancer; $P S A=$ prostate-specific antigen.

starting docetaxel. Peripheral neuropathy is another risk of chemotherapy, and it is potentially irreversible. ${ }^{11}$ If patients report warning signs and symptoms, it is recommended to reduce the dose of docetaxel to $60 \mathrm{mg} / \mathrm{m} 2 .^{12}$ If symptoms persist, further reduce the dose to $45 \mathrm{mg}$ or stop treatment.

Twenty-four to 72 hours before each infusion, obtain a complete blood count to confirm that neutrophils are at least 1500 cells/ $\mu \mathrm{L}$, hemoglobin is at least $100 \mathrm{~g} / \mathrm{L}$, and platelets exceed 100 x 109/L. Also obtain liver function tests. Typically, docetaxel can be continued as long as results do not exceed three times the upper limit of normal.

The novel taxane cabazitaxel is an alternative for treating docetaxel-resistant $\mathrm{mCRPC} .{ }^{13}$ In a recent noninferiority study, a fixed dose of $20 \mathrm{mg}$ cabazitaxel was equivalent to $25 \mathrm{mg} /$ $\mathrm{m} 2$ in terms of overall survival (OS) ${ }^{14}$ Patients should receive prednisone (5 mg twice daily) during cabazitaxel treatment. I do not exceed 10 cycles, and I consider adding G-CSF if patients are older than 75 years or have a history of docetaxel-induced neutropenic fever.

Next, let's consider chemotherapy in specific PC settings.

\section{MCRPC}

As the Prostate Cancer Clinical Trials Working Group 3 has noted, localized PC progresses to biomedical recurrence or to mHSPC, both of which ultimately become resistant to hormone therapy and are potential candidates for successive treatments. ${ }^{16}$ Thus, our concept of advanced prostate cancer has evolved beyond pre- and post-docetaxel to encompass multiple lines of therapy (Figure 1). ${ }^{16}$

In 2004, the pivotal, randomized phase III TAX 327 trial confirmed that docetaxel was superior to mitoxantrone for patients with $\mathrm{mCRPC} .{ }^{17}$ In an updated survival analysis, patients who received docetaxel (75 mg/m2 every 3 weeks) + prednisone (5 mg twice daily) had about a 25\% lower risk of death and about a 3-month longer median OS compared with patients who received prednisone + mitoxantrone (12 mg/m2 every 3 weeks). ${ }^{18}$

In 2010, cabazitaxel became the first agent to demonstrate a survival advantage among patients whose PC had progressed after docetaxel therapy. ${ }^{13}$ In the large, randomized multicenter TROPIC trial, patients with mCRPC who received cabazitaxel (25 $\mathrm{mg} / \mathrm{m} 2$ every 3 weeks) had a median OS of 15.1 months compared with 12.7 months among patients who received mitoxantrone, a 2.4-month difference. This translated to about a 30\% reduction in risk of death (hazard ratio [HR], 0.70; 95\% confidence interval [CI], 0.59 to $0.83 ; \mathrm{P}<.0001) .{ }^{13}$

Events that occurred at the beginning of the TROPIC study are worth noting: Clinics in countries that were not equipped to manage heavily pre-treated PC patients struggled to manage severe treatment-emergent adverse effects, such as neutropenic fever with concurrent diarrhea. ${ }^{13}$ Within the North American population, cabazitaxel conferred a more than $40 \%$ reduction in the risk of death, but in countries outside the United States and Europe, a number of deaths occurred before centers became informed about how to manage these patients. ${ }^{13}$ These events underscore the critical need to ensure adequate case volume, infrastructure, and time before venturing into chemotherapy.

These events underscore the critical need to ensure adequate case volume, infrastructure, and time before venturing into chemotherapy.

\section{EARLY PC}

The clear survival advantage of chemotherapy in late-stage $\mathrm{mCRPC}$ inspired investigators to explore its use in newly diagnosed $\mathrm{mPC}$ and as a second-line treatment for $\mathrm{mHSPC}$. In the 

and 55\% in the non-docetaxel arm, for a hazard ratio for death of 0.76.21 Docetaxel also appeared to improve metastasis-free survival ( $\mathrm{P}=.05)$ and 4-year OS (93\% vs. 89\%; $\mathrm{P}=.04)(\mathrm{HR}, 0.70$; $95 \%$ CI, 0.51 to 0.98$).{ }^{21}$

In another recent study, experts reviewed randomized clinical trials of docetaxel + standard of care in men with HSPC. ${ }^{22}$ In a meta-analysis of 2,348 patients with $\mathrm{M} 0$ disease, docetaxel was associated with an $8 \%$ reduction in treatment failure at 4 years (from $70 \%$ to $62 \%$ ). However, the HR for death did not favor docetaxel $(0.70 ; 95 \%$ CI, 0.61 to $0.81 ; \mathrm{P}<.0001) .{ }^{22}$ Such findings highlight the need to use techniques like genomics to better identify which patients with MO PC are most likely to benefit from chemotherapy.

These results are a step in the right direction, but for now, this regimen is not ready for prime time. In our multidisciplinary tumor board, we discuss chemotherapy for relatively young patients with aggressive, locally advanced PC, especially if there are signs of pelvic lymph node involvement.

In our multidisciplinary tumor board, we discuss chemotherapy for relatively young patients with aggressive, locally advanced $P C$, especially if there are signs of pelvic lymph node involvement.

\section{CHEMOTHERAPY IN THE ABIRATERONE/ ENZALUTAMIDE ERA}

The emergence of effective non-chemotherapy therapies for $\mathrm{mPC}$, such as abiraterone acetate and enzalutamide, raises the question of how best to sequence therapies. Do we start with chemotherapy, or with non-chemotherapy?

The phase III FIRSTANA study helped inform this question by testing docetaxel's effects in a truly first-line setting: Less than $2 \%$ of patients had received abiraterone or enzalutamide prior to study enrollment. ${ }^{23}$ In the study, which included 159 centers worldwide, 1,168 patients with chemotherapy-naïve mCRPC were randomly assigned to one of three regimens: cabazitaxel 20 mg/ $\mathrm{m} 2$, cabazitaxel $25 \mathrm{mg} / \mathrm{m} 2$, or docetaxel $75 \mathrm{mg} / \mathrm{m} 2$ every 3 weeks + daily prednisone $(10 \mathrm{mg}){ }^{23}$

Median OS was very similar among groups: 24.3 months (95\% CI, 22.2 to 27.6) for docetaxel, 24.5 months (95\% CI, 21.7 to 27.2) for cabazitaxel $20 \mathrm{mg}$, and 25.2 months (95\% CI, 22.9 to 27.0) for cabazitaxel $25 \mathrm{mg} / \mathrm{m} 2$. Thus, in 2017, we continue to project a survival time of only about 24 months when first treating mCRPC with docetaxel.

In contrast, in the randomized, phase III COU-302 trial of patients with chemotherapy-naïve $\mathrm{mCRPC}$, starting with abiraterone + prednisone and then proceeding to chemotherapy after progression led to a median OS of about 34.5-month, compared with 30.3 months in the placebo+prednisone arm (HR, $0.81 ; 95 \%$ CI, 0.70 to $0.93 ; \mathrm{P}=.003 .^{24}$

What about progression-free survival (PFS)? In the FIRSTANA trial, median PFS was 5.3 months ( $95 \%$ CI, 4.9 to 5.8) with docetaxel, which was similar to results in the cabazitaxel 20 mg/m2 (4.4 months; 3.9 to 5.1) and cabazitaxel 25 mg/m2 (5.1 months; 4.6 to 5.7) arms. ${ }^{23}$ In the COU-302 trial, median time to radiographic progression was 16.5 months among patients who received abiraterone+prednisone. ${ }^{24}$ In a separate trial of patients with chemotherapy-naïve mCRPC who received enzalutamide, ${ }^{25}$ and median time to progression was 18 months.

In FIRSTANA, PSA response rates were 68\% in the docetaxel group, $69 \%$ in the cabazitaxel $25 \mathrm{mg} / \mathrm{m} 2(\mathrm{P}=.99)$, and $61 \%$ in the cabazitaxel $20 \mathrm{mg} / \mathrm{m} 2$ group ( $\mathrm{P}=.052 \mathrm{vs}$. docetaxel $)^{23}$ — the best results we had ever seen in a first-line setting. The rate of tumor response based on RECIST criteria was 31\% with docetaxel, 32\% with cabazitaxel $20 \mathrm{mg} / \mathrm{m} 2$, and $42 \%$ with cabazitaxel $25 \mathrm{mg} / \mathrm{m} 2$. $^{23}$ In contrast, rates of PSA response were $78 \%$ with abiraterone and $69 \%$ with enzalutamide. ${ }^{24,25}$

Thus, abiraterone and enzalutamide appear to be at least as effective as docetaxel in treating mCRPC. We must also consider safety. Chemotherapy toxicities can be serious, but are relatively simple to manage given appropriate experience, infrastructure, and vigilance. In FIRSTANA, chemotherapy not infrequently led to grade 3-4 treatment-emergent adverse events, such as febrile neutropenia and diarrhea, toxicity stopped about a third of patients from completing treatment. ${ }^{23}$ In addition, $25 \%$ of patients developed docetaxel-emergent grade 1-2 peripheral neuropathy, which will progress without dose reduction or cessation. Rates of death linked to adverse events were $2 \%$ in the docetaxel group, $0.8 \%$ in the cabazitaxel $20 \mathrm{mg} / \mathrm{m} 2$ group, and $2.8 \%$ in the $25 \mathrm{mg} /$ m2 group, ${ }^{23}$ underscoring the importance of selecting patients who are well enough to receive chemotherapy.

So, in the abiraterone and enzalutamide era, is there still a role for upfront chemotherapy in the mCRPC setting? I would definitely say yes. Robust data support upfront chemotherapy in patients with $\mathrm{mCRPC}$ who have a clear disconnect between PSA and burden of disease. Tumors in patients who have a low PSA but a high burden of mPC clearly lack an androgen receptor therefore pose a much higher risk of treatment failure on hormonal therapy. Additional considerations for upfront chemotherapy include high burden of visceral metastases, rapidly progressive moderate to severe symptoms, minimal response to primary $\mathrm{AD}$, or androgen receptor splice variant-7 (AR-V7) in circulating tumor cells, which predicts worse outcomes in $\mathrm{mCRPC}{ }^{26}$ Together, these groups comprise about $10 \%$ to $20 \%$ of patients who walk through our doors.

Finally, we should keep in mind that chemotherapy can remain effective after $\mathrm{mCRPC}$ patients receive hormonal therapy. In a post-hoc analysis of COU-302, 265 patients received 



\section{SEQUENCING AND COMBINING CRPC THERAPIES What Does the Future Hold?}

By Charles J. Ryan, MD

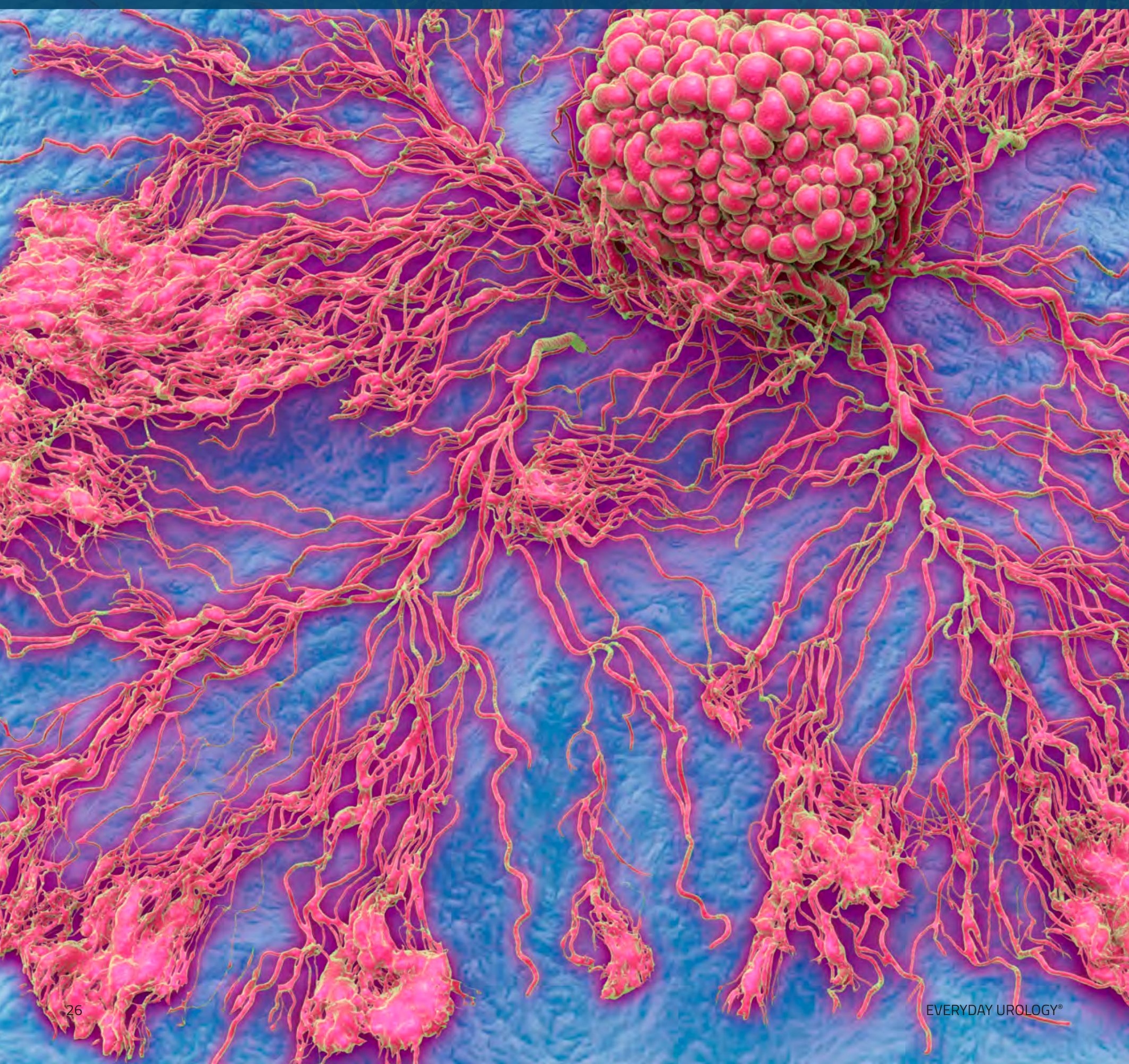



poor outcomes. It remains unclear whether this is because of biological differences in the tumor or because of morbidity to the liver itself. In a recent study of more than 8,000 men with $\mathrm{mCRPC}$ who were enrolled in phase III trials, patients with lymph-nodeonly disease had the best OS (median, 31.6 months; 95\% CI, 27.9 to 36.6 months), patients with lung and bone metastases had shorter and similar median OS (19.4 months [95\% CI, 17.8 to 20.7 months] vs. 21.3 months [20.8 to 21.9 ], respectively), and patients with liver metastases the worst OS (median, 13.5 months; $95 \% \mathrm{CI}$, 12.7 to 14.4 months). ${ }^{12}$

Studies of bone marrow, transuretheral resection of the prostate (TURP), and autopsy specimens indicate that CRPC is hypersensitive rather than resistant to $\mathrm{ADT}$. 13,14,15,16 Treatment-mediated selection pressure during ADT causes the androgen receptor to amplify, and to avoid adding fuel to the fire, we continue ADT in the CRPC setting. Treatment-mediated selection pressure also continues throughout the life of a tumor, further intensifying the need to correctly sequence therapies.

Both abiraterone and enzalutamide are highly active agents that have tremendous effects on progression-free survival (PFS), with a median of 17 months in recent trials comparing monotherapy with prednisone or placebo. ${ }^{8,17}$ However, it's crucial to remember these drugs only benefit patients who respond. A patient with CRPC who responds well to either therapy may survive without disease progression for 3 to 4 years, while someone who does not respond well is not benefiting and needs a change treatment. When I start a patient with early CRPC on abiraterone or enzalutamide, I see him again in 12 weeks. If his PSA level has not decreased, I stop the drug. This patient will not benefit from more time on abiraterone or enzalutamide; he probably has a subset of CRPC that requires greater biological attention. In my experience, about $15 \%$ of patients who receive abiraterone or enzalutamide do not respond to treatment — their rising PSA continues unchecked. I stop treating these patients. About another $10 \%$ of patients have a modest (less than 50\%) decline in PSA. I keep this latter group on treatment.

\section{SEQUENCING: WHAT WE KNOW}

Let's consider more data on sequencing therapies in CRPC. In a recent non-randomized retrospective study, researchers compared PFS, OS, and PSA responses from consecutive patients with chemotherapy-naïve $\mathrm{mCRPC}$ who received either abiraterone followed by enzalutamide ( $n=65$ ) or enzalutamide followed by abiraterone $(n=16) \cdot{ }^{18}$ The two groups were similar at baseline.

Initially, investigators observed a slight improvement in the patients who started with abiraterone and transitioned to enzalutamide. Median PFS was 19.5 months (15.5 to 22.3 months), vs. 13.0 months (95\% CI, 10.3 to 21.2 months) among patients who received enzalutamide followed by abiraterone. ${ }^{18}$ An expanded retrospective study made it clear that some patients responded to abiraterone but not enzalutamide, while others responded to enzalutamide but not abiraterone. ${ }^{19}$ Nonetheless, the general trend persisted: Patients who started with abiraterone and then transitioned to enzalutamide had somewhat better PFS (median, 455 days [95\% CI, 385 to 495 days]) than patients who started with enzalutamide and transitioned to abiraterone (median, 296 days; 95\% CI, 235 to 358 days). ${ }^{19}$ Overall survival did not significantly differ between group. ${ }^{19}$

More compelling initial data come from an ongoing, randomized, phase II study comparing abiraterone vs. enzalutamide in patients with treatment-naïve $\mathrm{mCRCP}{ }^{20}$ Patients crossed over to the other treatment arm when they first progressed. So far, median time to progression has been 7.4 months in each arm, suggesting that abiraterone and enzalutamide each offer one shot on goal. ${ }^{20}$

Therefore, I choose between abiraterone and enzalutamide based on the adverse effects I most want to avoid. Abiraterone is commonly associated with edema, so I avoid recommending it in patients with congestive heart failure. ${ }^{8}$ Enzalutamide is more likely than abiraterone to cause central nervous system toxicity, which can lead to fatigue and may be poorly tolerated in older patients. ${ }^{22}$ Thus, I tend to consider enzalutamide if patients have baseline edema or CHF, renal impairment, or diabetes, and abiraterone if patients are older, already are receiving multiple medications, or have substantial fatigue, a history of neurologic issues or falls, or mild pain that might benefit from low-dose steroids. Note that the norm with abiraterone is now once-daily treatment with $5 \mathrm{mg}$ prednisone, ${ }^{23}$ which is not a supraphysiologic dose and therefore should not affect treatment choice.

\section{WHEN TO START THERAPY}

The next question is when to start therapy. Among early-stage CRPC patients in the COU-302 Study whose PSA was less than 80 ng/mL, Brief Pain Inventory score was 0-1, and Gleason score was less than 8, those who received abiraterone typically survived almost 1 year longer than those who received placebo (median OS, 53.6 months vs. 41.8 months, respectively) (HR, 0.61; 95\% CI, 0.43 to $0.87 ; \mathrm{P}=.006) .{ }^{24}$ Thus, early-stage CRPC patients not only had a better prognosis than did patients with later-stage disease, they did better on abiraterone.

Among COU-302 patients with asymptomatic or mildly symptomatic mCRPC, baseline PSA < $15.6 \mathrm{ng} / \mathrm{mL}$ also was associated with a significantly lower hazard of progression (HR, 0.58; $95 \%$ CI, 0.46 to 0.74 ), death (HR, 0.53; 0.39 to 0.72 ), and time to PSA progression (HR, 0.63; 0.50 to 0.78) compared with baseline PSA > 106.2 ng/mL (P < .00l).26 Abiraterone also led to a faster rate and a greater degree of PSA decline than placebo. ${ }^{26}$

On the flip side, in an exploratory analysis of the randomized phase III COU-301 Study, abiraterone improved median OS to 13.9 months among patients with post-docetaxel mCRPC who had lung metastases, a 6-month improvement compared with prednisone alone. ${ }^{25}$ Abiraterone also improved median OS in patients 
patients who had DNA wild-type tumors.35 Median PFS was 13.8 months (95\% CI, 8.1 months to not reached) among patients with DNA repair-deficient tumors and 7.8 months (5.4 to 13.3 months) among patients with wild-type tumors $(\mathrm{P}=.01)$. Measurable disease and PSA response rates also were significantly better in patients with DNA repair-deficient tumors than in patients with wild-type tumors, with P-values of .009 and .02, respectively. Although this was a small trial, meaningful differences existed in both treatments arms. ${ }^{35}$ We can conclude that knowing the DNA repair mutation status of a patient with CRPC may be helpful before starting abiraterone.

Finally, let's consider luminal and basal subtyping, a useful approach to molecular subtyping that has been used for years in breast cancer. The PAM50 gene classification set is a group of genes that cluster breast cancer specimens into luminal A (LumA), luminal B (LumB), and basal subtypes, and PC specimens cluster very similarly. ${ }^{36}$ In a large study of pooled cohorts of patients who received hormone therapy and radiation for PC, hierarchical gene clustering and Kaplan-Meier curves showed that PAM50 gene clusters differed based on biochemical recurrence-free survival, distant metastasis-free survival, PC-specific survival, and OS. ${ }^{36}$ I predict that in the future, we will be able treat patients with PC based on the molecular and genomic "buckets" their cancers fall into.

\section{CONCLUSIONS}

Seven years of experience with AR targeting in men with CRPC show that it provides an opportunity for clinical benefit with low morbidity. Patterns of treatment resistance differ and may be driven by tumor biology. In the future, biopsies of metastases or circulating tumor DNA will be standard ways to understand disease biology and make treatment decisions. For now, proactive, risk-adapted treatment of CRPC is personalized medicine.

\section{REFERENCES}

1. European Association of Urology. Prostate cancer (guideline). http://uroweb.org/guideline/prostate-cancer/ Accessed Dec 3, 2017.

2. Sweeney C, Chen Y-H, Liu G, et al. Long-term efficacy and QOL data of chemohormonal therapy (C-HT) in low and high-volume hormone naïve metastatic prostate cancer (PrCa): E3805 CHAARTED trial. Ann Oncol 2016;27(suppl_6):720PD.

3. Halabi S, Lin CY, Kelly WK, et al. Updated prognostic model for predicting overall survival in first-line chemotherapy for patients with metastatic castration-resistant prostate cancer. J Clin Oncol 2014;32(7):671-677

4. Moreira DM, Howard LE, Sourbeer KN, et al. Predicting time from metastasis to overall survival in castration-resistant prostate cancer: results from SEARCH. Clin Genitourin Cancer 2017;15(1):60-66 5. Oh WK, Miao R, Vekeman F, et al. Patient characteristics and overall survival in patients with post-docetaxel metastatic castration-resistant prostate cancer in the community setting. Med Oncol 2017;34(9):160

6. Koo KC, Park SU, Kim KH, et al. Predictors of survival in prostate cancer patients with bone metastasis and extremely high prostate-specific antigen levels. Prostate Int 2015;3(1):10-5

7. Ryan CJ, Kheoh T, Li J, et al. Prognostic index model for progression-free survival in chemotherapy-naïve metastatic castration-resistant prostate cancer treated with abiraterone acetate plus prednisone. Clin Genitourin Cancer. 2017 Jul 25. pii: S1558-7673(17)30211-2. [Epub ahead of print] 8. Ryan CJ, Smith MR, De bono JS, et al. Abiraterone in metastatic prostate cancer without previous chemotherapy. N Engl J Med 2013;368(2):138-148.

9. Petrylak DP, Tangen CM, Hussain MH, et al. Docetaxel and estramustine compared with mitoxantrone and prednisone for advanced refractory prostate cancer. N Engl J Med 2004;351:1513-1520.
10. Tannock IF, de Wit R, Berry WR, et al. Docetaxel plus prednisone or mitoxantrone plus prednisone for advanced prostate cancer. N Engl J Med. 2004;351:1502-1512.

11. NCCN Clinical Practice Guidelines in Oncology. Version 2.2017. https://www.nccn.org/professionals/ physician_gls/PDF/prostate.pdf

12. Halabi S, Kelly WK, Ma H, et al. Meta-analysis evaluating the impact of site of metastasis on overall survival in men with castration-resistant prostate cancer. J Clin Oncol 2016;34(14):1652-1659.

13. Mohler JL, Titus MA, Bai S, et al. Activation of the androgen receptor by intratumoral bioconversion of androstanediol to dihydrotestosterone in prostate cancer. Cancer Res 2011;71(4):1486-1496.

14. Stanbrough M, Bubley GJ, Ross K, et al. Increased expression of genes converting adrenal androgens to testosterone in androgen-independent prostate cancer. Cancer Res 2006;66(5):2815-2825.

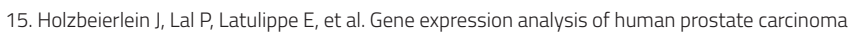
during hormonal therapy identifies androgen-responsive genes and mechanisms of therapy resistance. Am J Pathol 2004;164(1):217-227

16. Friedlander TW, Roy R, Tomlins SA, et al. Common structural and epigenetic changes in the genome of castration-resistant prostate cancer. Cancer Res 2012;72(3):616-625.

17. Beer TM, Tombal B. Enzalutamide in metastatic prostate cancer before chemotherapy. N Engl J Med 2014;371(18):1755-1756.

18. Maughan BL, Luber B, Nadal R, et al. Comparing sequencing of abiraterone and enzalutamide in men with metastatic castration-resistant prostate cancer: a retrospective study. Prostate 2017;77(1):33-40.

19. Terada N, Maughan BL, Akamatsu S, et al. Exploring the optimal sequence of abiraterone and enzalutamide in patients with chemotherapy-naive castration-resistant prostate cancer: The KyotoBaltimore collaboration. Int J Urol 2017;24(6):441-448

20. Chi KN, Annala M, Sunderland K, et al. A randomized phase Il cross-over study of abiraterone + prednisone (ABI) vs enzalutamide (ENZ) for patients (pts) with metastatic, castration-resistant prostate cancer (mCRPC). J Clin Oncol 2017;35(suppl 15):abstr 5002.

21. Assessment of central nervous system (CNS) and dose reduction events in patients treated with abiraterone acetate plus prednisone (AA+P) or enzalutamide (ENZ).

22. Pilon D, Behl AS, Gozalo L, et al. Assessment of central nervous system (CNS) and dose reduction events in patients treated with abiraterone acetate plus prednisone (AA+P) or enzalutamide (ENZ). J Clin Oncol 2016;34(suppl 15):abstr 5078.

23. Fizazi K, Tran N, Fein L, et al. Abiraterone plus prednisone in metastatic, castration-sensitive prostate cancer. N Engl J Med 2017; 377(4):352-360.

24. Miller K, Carles J, Gschwend JE, et al. The phase 3 COU-AA-302 study of abiraterone acetate (AA) in men with chemotherapy (CT)-naiive metastatic castration-resistant prostate cancer (mCRPC): Stratified analysis based on pain, prostate-specific antigen (PSA) and Gleason score (GS). Eur Urol Suppl 2016;15(3):abstr 775.

25. Goodman OB, Flaig TW, Molina A, et al. Exploratory analysis of the visceral disease subgroup in a phase III study of abiraterone acetate in metastatic castration-resistant prostate cancer. Prostate Cancer Prostatic Dis 2014;17(1):34-39.

26. Ryan C, Londhe A, Molina A, et al. Relationship of baseline PSA and degree of PSA decline to radiographic progression-free survival (rPFS) in patients with chemotherapy-naive metastatic castration-resistant prostate cancer (mCRPC): Results from COU-AA-302. J Clin Oncol 2013;31(suppl):abstr 5010.

27. Scher HI, Morris MJ, Basch E, Heller G. End points and outcomes in castration-resistant prostate cancer: from clinical trials to clinical practice. J Clin Oncol 2011;29(27):3695-3704.

28. Scher HI, Morris MJ, Stadler WM, et al. Trial design and objectives for castration-resistant prostate cancer: updated recommendations from the Prostate Cancer Clinical Trials Working Group 3. J Clin Oncol. 2016;34(12):1402-1418.

29. Attard G, Borre M, Gurney H, et al. A phase IV, randomized, double-blind, placebo (PBO)-controlled study of continued enzalutamide (ENZA) post prostate-specific antigen (PSA) progression in men with chemotherapy-naive metastatic castration-resistant prostate cancer (mCRPC). J Clin Oncol 2017;35(suppl 15):abstr 5004

30. Ryan CJ, Smith MR, De Bono JS, et al. Interim analysis (IA) results of COU-AA-302, a randomized, phase III study of abiraterone acetate (AA) in chemotherapy-naive patients (pts) with metastatic castration-resistant prostate cancer (mCRPC). J Clin Oncol 2012;30(suppl 18):abstr LBA4518.

31. Small EJ, Huang J, Youngren J, et al. Characterization of neuroendocrine prostate cancer (NEPC) in patients with metastatic castration resistant prostate cancer (mCRPC) resistant to abiraterone (Abi) or enzalutamide (Enz): Preliminary results from the SU2C/PCF/AACR West Coast Prostate Cancer Dream Team (WCDT). J Clin Oncol 2015;33(suppl 15): abstr 5003.

32. Robinson D, Van Allen EM, Wu YM, et al. Integrative clinical genomics of advanced prostate cancer Cell 2015; 161(5):1215-1228.

33. Nelson WG, De Marzo AM, Yegnasubramanian S. Epigenetic alterations in human prostate cancers. Endocrinology 2009; 150(9): 3991-4002. https:/www.ncbi.nlm.nih.gov/pmc/articles/PMC2736081/

34. Banks P, Xu W, Murphy D, et al. Relevance of DNA damage repair in the management of prostate cancer. Curr Probl Cancer 2017;41(4):287-301. http://www.sciencedirect.com/science/article/pii/ S0147027217301022

35. Hussain M, Daignault S, Twardowski P, et al. Abiraterone + prednisone (Abi) +/- veliparib (Vel) for patients (pts) with metastatic castration-resistant prostate cancer (CRPC): NCl 9012 updated clinical and genomics data. J Clin Oncol 2017;35(suppl): abstr 5001.

36. Zhao SG, Chang SL, Erho N, et al. Associations of luminal and basal subtyping of prostate cancer with prognosis and response to androgen deprivation therapy. JAMA Oncol. 2017 May 11. doi: 10.1001/ jamaoncol.2017.0751. [Epub ahead of print] 


\section{Société Internationale d'Urologie 2017}

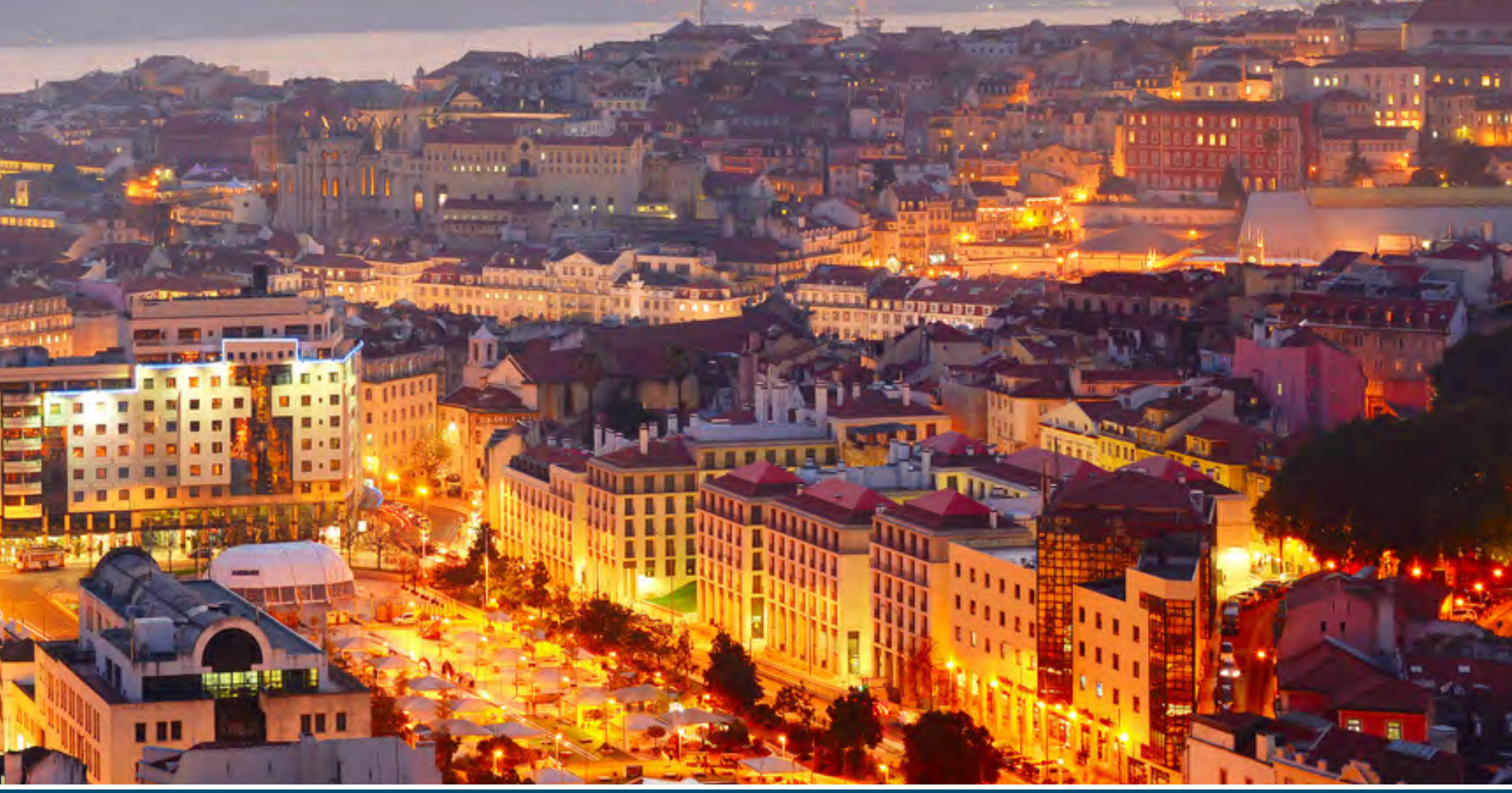

\section{SIU 2017 // October 19-22, 2017 // Lisbon, Portugal}

This issue's Spotlight section features highlights in the area of prostate, bladder and kidney cancer from the 37th Congress of Société Internationale d'Urologie (SIU 2017). Key coverage in the area of bladder cancer that was featured was from the SIU-ICUD Joint Consultation on Bladder Cancer. In this section, topics included, epidemiology, prevention, screening, diagnosing and evaluation of bladder cancer presented by Ashish Kamat, MD. Another highlighted session was by Badrinath Konety on non-urothelial cancer of the urinary bladder. For complete coverage of the SIU meeting please visit www.urotoday.com/conference-highlights/siu-2017. 


\section{Radiogenomics, Magnetic Resonance Imaging, and Prostate Cancer Imaging}

Dr. Robert Reiter discussed a new field called radiogenomics, which is the use of genomics in conjunction with imaging to make management decisions in prostate cancer $(P C)$.

He reviewed some of the talks from earlier in the localized PC session, focusing on the use of markers. Dr. Reiter then coupled this with what we know already about the utility of multiparametric magnetic resonance imaging (mpMRI) in the evaluation and management of PC. However, the combination of these two may provide greater utility than either one alone.

Questions that arise:

1. What is the role of genomic testing, and how should it be utilized in the setting of multiparametric MRI and targeted biopsy?

" Does genomic testing help risk stratify?

- Can this form of testing provide information independent of PI-RADS scoring?

2. What are the biological determinants that underlie MRI findings?

- Can an integrated radiogenomic prognostic/predictive tool be created? Radiomics?

Oncotype DX Genomic Prostate Score (GPS)

" 17-gene reverse transcription-polymerase chain reactionbased assay

- Validated as an independent predictor of adverse pathology at the time of radical prostatectomy-Gleason $4+3$ or higher, pT3+

- Dr. Reiter performed a study using GPS after having had an mpMRI-guided systematic biopsy prior to radical prostatectomy, which is done in men with low/intermediate-risk PC

" On multivariate analysis, GPS score (more than PI-RADS score) was the strongest predictor of adverse pathology and independent of traditional clinicopathologic features

- Gleason score + GPS area under the curve 0.79essentially the same when you add MRI

" Hence, MRI did not necessarily add much (for low/intermediaterisk disease)

\section{" But GPS score did correlate with PI-RADS score}

Radiomics - association with quantitative imaging features with genomics

\section{" 2 studies (UCLA and Miami)}

- UCLA study-MRI evaluation of the prostate and MRI-guided biopsy of the prostate in 6 patients.

- Immunohistochemistry and gene expression analysis from the prostate tissue

" Correlate with detailed examination of the MRI imaging and mapping of the prostate
- Whole-exome sequencing of the normal-appearing tissue and concerning areas

- Researchers found that whole-exome sequencing identified cancer-related mutations both in the tumor and in areas thought to be normal, thereby supporting the concept of "field effect" in PC

- But no correlation with MRI features and specific mutations

" Miami study -

- PC-associated signatures on Decipher, GPS, and Prolaris correlated with radiomic features

- The transition zone and the peripheral zone have distinct radiomic features

- Apparent diffusion coefficient values most significantly associated with distinct biological processes

More work needs to be done in these areas.

PRESENTED BY: ROBERT REITER, MD, GEFFEN SCHOOL OF MEDICINE AT UCLA, LOS ANGELES, CALIFORNIA

WRITTEN BY: THENAPPAN CHANDRASEKAR, MD, CLINICAL FELLOW, UNIVERSITY OF TORONTO, TORONTO, ONTARIO, CANADA

\section{Routine Use of Adjuvant Radiation After Radical Prostatectomy for Positive Surgical Margin: Not for All!}

Dr. Marc Dall'era highlighted several important arguments as to why adjuvant treatment is not for every man: not all patients with positive surgical margin (PSM) recur; not all PSM are the same; early salvage may be just as good; there is a significant cost of adjuvant radiotherapy; and an argument can be made for novel imaging and biomarkers that will help identify men at risk, who should be treated.

Dr. Dall'era covered the three prospective, randomized trials assessing adjuvant radiotherapy after radical prostatectomy. These include Southwest Oncology Group or SWOG 87-94, European Organisation for Research and Treatment of Cancer or EORTC 22911, and a German trial labeled ARO 96-02. According to Dr. Dall'era, $30 \%$ to $35 \%$ of men in the SWOG and EORTC trials had persistent prostate-specific antigen (PSA) after radical prostatectomy, making radiation treatment fall under the category of salvage and not adjuvant. Furthermore, only ARO 96-02 required undetectable PSA at enrollment. In addition, a substantial number of individuals in the control arm of these trials never experienced a recurrence. Only the SWOG Trial showed an overall survival advantage for adjuvant radiotherapy, and lastly, the patients in the control arms of all these trials generally received salvage radiotherapy later on.

He observed that these three randomized trials did not answer the question of whether all men with PSM require adjuvant radiotherapy. Some retrospective data show that up to $45 \%$ of patients with PSM 
will not recur in a follow-up time of more than 10 years. Recent evidence also demonstrates that after 20 years of follow-up, no difference was seen in distant metastasis and overall survival in patients with PSM who received adjuvant radiotherapy compared with those who did not. There is a difference in the types of PSM, and it is also known that a Gleason score of four and higher at the margin has a far more substantial risk of prostate cancer-specific mortality than lower Gleason scores.

A description on the Decipher genomic classifier test was also given as a potential way to mark those patients at risk for recurrence, who should be treated with adjuvant radiotherapy. Also, the usage of ultrasensitive PSA could be enlisted to help determine who needs to be treated. Almost $100 \%$ of men with any postoperative ultrasensitive PSA over 0.03 had eventual clinical biochemical recurrence.

Dr. Dall'era summarized these points: not all men with PSM recur and not everyone with biochemical recurrence progresses to clinical recurrences or death. According to Dr. Dall'era, it is important to adopt a risk-stratified approach and take into account the grade and length of PSM, to note the value of ultrasensitive PSA at three months postoperatively, to measure time to PSA recurrence, and to use novel biomarkers and imaging to improve care and choose the appropriate patients for adjuvant radiotherapy. In conclusion, he advised that early salvage radiotherapy may work just as well with less overtreatment.

PRESENTED BY: MARC DALL'ERA, MD, UC DAVIS HEALTH, SACRAMENTO, CALIFORNIA WRITTEN BY: HANAN GOLDBERG, MD, UROLOGIC ONCOLOGY FELLOW (SOCIETY OF UROLOGIC ONCOLOGY), UNIVERSITY OF TORONTO, PRINCESS MARGARET CANCER CENTRE, TORONTO, ONTARIO, CANADA

\section{Survival Outcomes of Younger Men (55 Years) Undergoing Radical Prostatectomy}

Dr. Luke Wang indicated that while prostate cancer $(P C)$ is typically a disease of older men, its prevalence increases with each decade of life. Therefore, PC can and does occur in younger individuals. As these men are younger, treatment options are usually more easily accessible and more varied. However, quality of life also plays an important role.

In this study, the authors focused on younger men (age < 55) diagnosed with PC to identify how they differed from their older counterparts. Specifically, they put the spotlight on the outcomes of patients younger than 55 years of age who had undergone radical prostatectomy. Data were obtained from the Victorian Cancer Registry, which encompassed all patients who received a cancer diagnosis from 2004 to 2014 in Victoria, Australia. In that time period, 109 individuals were between ages 35 and 44, with 1,998 between ages 45 and 54 . These men were then compared with those whose age range ran from 55 to 74 years.
On univariate analysis, men under age 55 had higher rates of Gleason scores of 7 or less and cT2 disease or less, while having similar median PSA values at the time of diagnosis. On multivariate analysis, when adjusting for Gleason grade, T-stage, and PSA, patients between 45 and 54 had an improved overall survival (OS), but this difference was not observed in men aged 35 to 44. The 5and 10-year OS was higher for men 45 to 54 than those aged 55 to 74. Unfortunately, the multivariate analysis was not listed, so these results could not be verified.

However, in terms of adverse events and five and ten-year cancerspecific survival, younger men had far fewer negative side effects and much better cancer-specific survival.

There are many questions that need to be addressed. First, what was the median follow-up? Young patients are unlikely to die of other causes in that same time frame; hence, OS may not be a very good outcome to measure. In addition, much younger patients who develop PC may have some genetic predisposition that was never determined, which might affect the survival outcomes. Stagematched survival also would have been a more useful factor to present. Further analysis needs to be done to find the differences.

PRESENTED BY: LUKE WANG, MD, EASTERN HEALTH, VICTORIA, AUSTRALIA WRITTEN BY: THENAPPAN CHANDRASEKAR, MD, CLINICAL FELLOW, UNIVERSITY OF TORONTO, TORONTO, ONTARIO, CANADA

\section{PSMA Positivity in Metastatic Prostate Cancer: A Morphologic Bias?}

The prostate-specific membrane antigen-positron emission tomography (PSMA-PET) Scan is becoming increasingly popular in the setting of biochemical recurrence after prostate cancer $(P C)$ definitive therapy (external-beam radiation therapy or radical prostatectomy) for identification of low-volume metastatic disease. However, while better than conventional imaging, this particular scan is not perfect.

In this study, the authors attempted to correlate PSMA-PET avidity to $P C$ histology. To that end, they assessed retrospectively a patient cohort that had undergone salvage template pelvic lymph node dissection for oligometastatic disease following definitive local therapy and biochemical recurrence.

Of 66 patients with such recurrence, 20 were found to be PSMA-PET avid and underwent salvage lymph node dissection. Mean prostatespecific antigen was 2.49 at the time of oligometastatic diagnosis. All 20 men were found to have metastatic PC at the time of diagnosis. Of those 20 patients, 16 had exhibited prominent cribriform architecture, with 11 having a 100\% cribriform pattern. In particular, this was most commonly seen with ductal adenocarcinoma or acinar adenocarcinoma.

While interesting, obviously this result represents a small series. This would be interesting to compare with a series in which PSMA was 


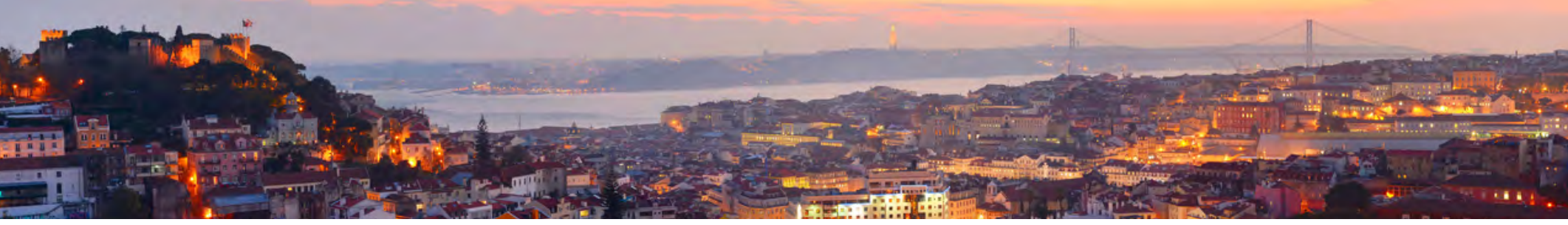

completed prior to prostatectomy to observe whether similar results were found. Also notable is the finding of ductal adenocarcinoma, as this tends to be an aggressive disease, sometimes without much of a rise in prostate-specific antigen. Future follow-up from this study will most definitely be valuable.

PRESENTED BY: DANIEL CHRISTIDIS, BDC, AUSTIN HEALTH, MELBOURNE, AUSTRALIA WRITTEN BY: THENAPPAN CHANDRASEKAR, MD, CLINICAL FELLOW, UNIVERSITY OF TORONTO, TORONTO, ONTARIO, CANADA

\section{Bone-Targeted Treatment in Advanced Prostate Cancer}

While the number of treatment options continues to grow, it is important to consider the potential implications of these forms of therapy. Many of them will significantly affect bone health, which can have a lasting impact on patients and lead to significant complications, including death.

Bone metastases can cause pathologic fracture and spinal cord compression, and treatment may involve invasive surgery or radiotherapy. Skeletal-related events (SREs) encompass all the above, with almost every patient experiencing at least one SRE prior to death. These SREs will recur with the new therapies.

Interestingly, more recent data also suggest that prostate metastases can yield new metastases, hence, both bone metastases control and bone microenvironment understanding are important moving forward. All of the current therapies have a direct or indirect effect on the bone microenvironment.

Bone-targeting therapies have demonstrated the following:

\section{Reduced SREs}

\section{Longer time to first SRE}

3. Likely improved overall survival (OS) (studies hint at this)

At this time, it is only indicated for metastatic castration-resistant prostate cancer $(\mathrm{PC})$. There is no indication for metastatic hormonesensitive PC.

Recent studies have demonstrated denosumab is clearly superior to zoledronic acid in a randomized, controlled trial, with an $18 \%$ risk reduction in time to first $\mathrm{SRE}$.

\section{BURDEN OF DISEASE}

Dr. Fred Saad addressed a Canadian study that looked at the financial burden of SREs and treatment. Median survival of two years from SRE to death. Some $70 \%$ of patients had at least one symptomatic event before dying. The event rate was 50\% in those on bonetargeted therapy. The cost of SREs is three-fold in men with SRE compared with individuals with no SRE.
" Radium-223 (ALpharadin in SYMPtomatic prostate Cancer [ALSYMPCA]) Trial

" Reviewed the key findings from this trial

" Quality of life improved on Radium-223

" Time to first SRE was extended

" Patients who receive five to six versus one to four infusions (or placebo) have significant OS benefit

\section{- Alkaline phosphatase decline is a reliable marker of improved response}

- Asymptomatic patients at baseline did better than men symptomatic at baseline

- Eastern Cooperative Oncology Group 2 patients did much worse than the group's 0-1 patients

- Combining with abiraterone/enzalutamide or denosumab improved OS more than monotherapy alone

Dr. Saad did note that older, bone-targeted therapies did demonstrate a benefit in teaming with other systemic therapies in an earlier PC space, so perhaps there is a role for Radium-223 in an earlier space as well as in conjunction with established therapies?

There are two randomized, prospective studies combining with abiraterone and enzalutamide in hormone-sensitive space, with one already completed (results pending) and the other ongoing.

PRESENTED BY: FRED SAAD, MD, UNIVERSITY OF MONTREAL HOSPITAL CENTERS MONTREAL, QUEBEC, CANADA

WRITTEN BY: THENAPPAN CHANDRASEKAR, MD, CLINICAL FELLOW, UNIVERSITY OF TORONTO, TORONTO, ONTARIO, CANADA

\section{Role of Growth Hormone-Releasing Hormone on Prostate Cancer}

Dr. Angeles Sanchís-Bonet described the involvement of growth hormone-releasing hormone $(\mathrm{GHRH})$ and its receptors in several relevant processes that contribute to prostate cancer progression. However, the role of such a neuropeptide on cell transformation through epithelial-mesenchymal transition is still unknown. In this study, the authors aimed to compare the expression of GHRH receptors and their splice variants (SVs) as well as to study the carcinogenic potential of GHRH on human prostate cells.

The authors used the nonmalignant human prostate epithelial cell line RWPE-1. The expression of GHRH receptors and their SVs was evaluated by Western blot analysis and Immunocytochemistry. To assess the effect of the neuropeptide on tumorigenic capability, these researchers exposed some of the nontumor cells to $0.1 \mathrm{mM}$ $\mathrm{GHRH}$ for 24 hours. Then, cells were injected subcutaneously into the flank of nude mice, and the animals were divided into two groups: control group (10 mice) and GHRH group (8 mice). Tumor volume was assessed every week. 
Higher expression levels of GHRH receptors were detected in RWPE-1 when compared with levels of SVs. Tumor masses were evident in 7 of the 8 mice injected with RWPE-1 cells that were exposed to GHRH.

In conclusion, Dr. Sanchís-Bonet noted that GHRH acts as a proliferative agent in RWPE-1 cell transformation, conceivably through epithelial-mesenchymal transition, which reinforces GHRH's role in prostate tumorigenesis.

PRESENTED BY: ANGELES SANCHÍS-BONET, MD, HOSPITAL UNIVERSITARIO PRINCIPE DE ASTURIAS, MADRID, SPAIN

WRITTEN BY: HANAN GOLDBERG, MD, UROLOGIC ONCOLOGY FELLOW (SOCIETY OF UROLOGIC ONCOLOGY), UNIVERSITY OF TORONTO, PRINCESS MARGARET CANCER CENTRE, TORONTO, ONTARIO, CANADA

\section{Non-Androgen-Receptor-Targeted Options for Metastatic Castration-Resistant Prostate} Cancer

The CHAARTED and STAMPEDE studies demonstrated that administration of docetaxel in metastatic hormone-sensitive prostate cancer ( $\mathrm{mHSPC}$ ) reduced the risk of death by 39\%, creating a trend of giving these advanced lines of treatment earlier than in the past. Therefore, Dr. Fred Saad asked the following question: Since androgen deprivation therapy (ADT) is the standard first-line treatment of metastatic castration-resistant prostate cancer (mCRPC), is chemotherapy effective after hormonal therapy? The COU-AA-302 Study examined this question by administering docetaxel post-abiraterone and demonstrating a prostate-specific antigen fall by $50 \%$ in almost one-half of the patients. Another study, TROPIC, analyzed the administration of cabazitaxel after docetaxel and compared it to mitoxantrone. This study also had positive results with the increase of overall survival by a median of 2.4 months.

Chemotherapy should be given up-front in MCRPC patients with a high burden of disease with low PSA, high burden visceral metastases, moderate-severe symptoms, minimal response to primary ADT, and perhaps to known androgen receptor-variant- 7 splice variants. All of these represent approximately $10 \%$ to $20 \%$ of patients.

Dr. Saad later discussed the problems associated with bone metastases, which cause most of the morbidity and increased mortality. These problems include pathologic fractures and spinal cord compression, which lead to palliative radiotherapy and surgery to the bone. Keep in mind that zoledronic acid and denosumab significantly delay and reduce the risk posed by bone metastases. He also mentioned Radium-223 alpha-emitter therapy, which has been shown in the ALSYMPCA (ALpharadin in SYMPtomatic prostate (Ancer) Trial to improve overall survival and reduce the time to first symptomatic skeletal event after five to six injections when compared with placebo. Quite importantly, benefit has also been shown when bone-targeted therapy is combined with abiraterone in chemo-naïve mCRPC patients in the COU-AA 302 trial. Similarly, the TRAPEZE Trial demonstrated that in those with MCRPC, the teaming of docetaxel and zoledronic acid improves skeletal related event-free survival, and combining bone-targeted therapies with Radium-223 has also been shown to be beneficial. These drug combinations are the future of trials in this realm of PC, according to Dr. Saad.

He concluded by stating that thus far, immunotherapy, which includes cytotoxic T-lymphocyte-associated antigen-4 inhibition, programmed death-1 blockade, and vaccines, has been disappointing in PC. Dr. Saad also mentioned the trial he is conducting, which will assess the effect of physical exercise on the survival of mCRPC patients, adding that the future of metastatic hormone-sensitive PC and mCRPC should encompass trials that assess novel, targeted, and multimodal therapies.

PRESENTED BY: FRED SAAD, MD, UNIVERSITY OF MONTREAL HOSPITAL CENTERS, MONTREAL, QUEBEC, CANADA

WRITTEN BY: HANAN GOLDBERG, MD, UROLOGIC ONCOLOGY FELLOW (SOCIETY OF UROLOGIC ONCOLOGY), UNIVERSITY OF TORONTO, PRINCESS MARGARET CANCER CENTRE, TORONTO, ONTARIO, CANADA

\section{Demystifying the Mechanistic and Functional Aspects of RNA Activation with Double- Stranded RNAs in Human Prostate Cancer Cells}

The recently identified phenomenon of double-stranded RNA (dsRNA)-mediated gene activation (RNAa) has been studied extensively. It is present in humans, mice, and Caenorhabditis elegans (a transparent roundworm), suggesting that dsRNAmediated RNAa is an evolutionary mechanism.

Previous studies showed that dsP21-322 has the capacity to induce tumor suppressor gene p21 expression in human prostate cancer (PC) cells. Nonetheless, the role of dsRNAs in the activation of gene expression, including their target molecules and associated key factors, remains poorly understood.

In this study, human PC cell lines PC-3 and DU-145 were analyzed. Oligonucleotides were used to overexpress dsRNAs and dsControl. Real-time polymerase chain reaction and Western blot were used to detect mRNA and protein expression, respectively. Using fluorescence microscopy, the authors examined the kinetics of dsRNA subcellular distribution. Using a well-characterized antibody that recognizes biotin protein, they performed chromatin immunoprecipitation to detect the molecular target for dsR21322. Luciferase reporter assay was further performed to verify dsRNAs target molecules. In addition, co-immunoprecipitation, sliver-staining, tandem mass spectrometry, and chromatin immunoprecipitation assay were all carried out to identify unknown proteins and whether histone modification is involved in small activating RNA-mediated p21 expression. 


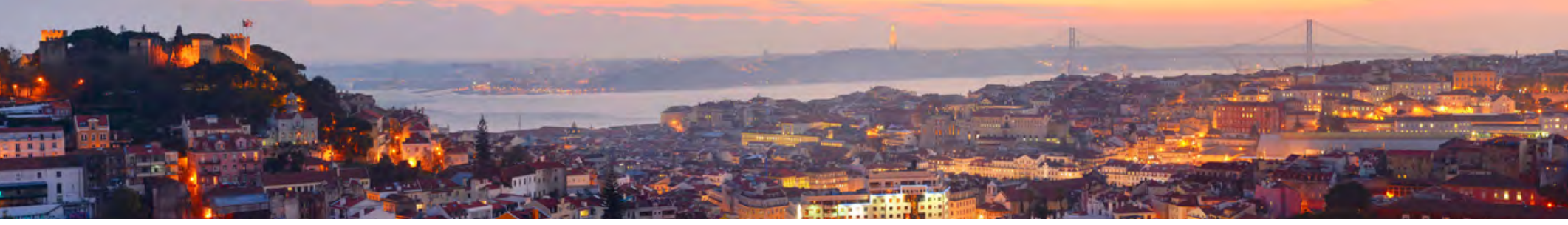

It was demonstrated that dsRNA-mediated p21 induction in human cell lines is a common phenomenon. This process occurs at the transcriptional level, with the complementary p21 promoter being the intended dsRNA target. Also, the authors recognized that several heterogeneous nuclear ribonucleoproteins associate with the dsP21-322.

In conclusion, the data reveal the mechanistic and functional aspects of non-coding RNA-mediated p21 activation in human PC cells. This might be a useful tool to analyze gene function and aid in the development of novel drug targets for PC treatment.

PRESENTED BY: JIM HU, MD, WEILL CORNELL MEDICINE, NEW YORK, NEW YORK WRITTEN BY: HANAN GOLDBERG, MD, UROLOGIC ONCOLOGY FELLOW (SOCIETY OF UROLOGIC ONCOLOGY), UNIVERSITY OF TORONTO, PRINCESS MARGARET CANCER CENTRE, TORONTO, ONTARIO, CANADA

\section{Prostate-Specific Membrane Antigen- Radioguided Surgery for Metastatic Lymph Nodes in Prostate Cancer}

Three well-respected urologic oncologists were asked to speak about the single most important observation in the recent past, with each of them choosing the area they felt represented the most exciting discovery.

In this first major observation, Dr. Markus Graefen discussed the role of prostate-specific membrane antigen (PSMA)-guided surgery for metastatic lymph nodes in prostate cancer.

He focused on the series by Rauscher et al, ${ }_{1}^{1}$ in which they pretreated patients with technetium-111 a day prior to surgery. The researchers then tracked the tissue intra-operatively during their salvage lymphadenectomy for recurrent prostate cancer and went on to correlate resected tissue and histopathologic results. More importantly, these colleagues also determined the efficacy (prostatespecific antigen [PSA] response without additional therapy).

Specifically, these were patients with recurrence after local definitive therapy (radiation or surgery). With low PSA levels, they often got PSMA positron emission tomography (PET) scans, with some found to have oligometastatic disease in the pelvis that might be amenable to resection. In such patients, the authors pretreated them with the agent one day before surgery. Intra-operatively, they tracked the signal based on counts of the technetium with the use of a sterile probe, which was similar to a sentinel lymph node dissection for breast cancer. The tissue could be histologically evaluated once outside the body to confirm the presence of the tracked molecule and be recorded in the absence of background noise, thereby serving as rapid confirmation of accurate resection.

The initial study had 31 patients, but in a recent update pending publication, there are reportedly now up to 120 men. These individuals had a pre-salvage PSA of $1.3 ; 93 \%$ had primary surgery, but $70 \%$ of them had some secondary therapy (radiation, hormones, or a combination). The researchers then went on to compare ex-vivo radioactivity with histopathologic findings and also determined PSA response without any planned adjuvant therapy, treatment-free survival, or complications.

In terms of results, 30 of 31 lesions were detected using a gamma probe. Exactly 145 were removed, with 51 histologically proven metastatic sites. In ex vivo analysis, 48 lesions were accurately identified as metastatic. Eighty-seven of the negative ones were correctly identified, but there were four false-negatives and six false-positives. Test characteristics: $92 \%$ sensitivity, 94\% specificity, accuracy $93 \%$, positive predictive value $89 \%$, negative predictive value $96 \%$.

Looking at best PSA response, 29 patients had good PSA response. A PSA reduction was greater than $50 \%$ in $70 \%$ of patients. A PSA response of more than $90 \%$ was seen in $53 \%$ of men, and $60 \%$ had a PSA of less than 0.2 , with PSA responses not noted in just two patients. Approximately 33\% went on to additional treatment at 125 days, while $67 \%$ had no further therapy over the next year. In terms of complications, four patients (13\%) had Grade 3 complications.

Take-home messages:

1. High value of PSMA in Radioguided surgery (RGS) to identify small metastatic sites

2. RGS may be even more precise than a PSMA PET scan as RGS identified five lesions not picked up with PSMA PET

3. Promising short-term outcomes with an acceptable morbidity profile

4. Patients must be well-selected.

PRESENTED BY: MARKUS GRAEFEN, MD, MARTINI-KLINIK, HAMBURG, GERMANY WRITTEN BY: HANAN GOLDBERG, MD, UROLOGIC ONCOLOGY FELLOW (SOCIETY OF UROLOGIC ONCOLOGY), UNIVERSITY OF TORONTO, PRINCESS MARGARET CANCER CENTRE, TORONTO, ONTARIO, CANADA

\section{REFERENCE}

1. Value of $111 \mathrm{ln}$-prostate-specific membrane antigen (PSMA)-radioguided surgery for salvage lymphadenectomy in recurrent prostate cancer: correlation with histopathology and clinical follow-up. Rauscher l, Düwel C, Wirtz M, et al. BJU Int. 2017;120:40-47. 
Joint Consultation on Bladder CancerEpidemiology, Prevention, Screening, Diagnosis and Evaluation

Dr. Ashish Kamat presented the Epidemiology, Prevention, Screening, Diagnosis, and Evaluation Chapter, and since the 2012 edition, there have been very few Level 1 studies in this field. However, there have been many Level 2 and 3 studies. As such, most of the new recommendations are Grade C, with several being Grade B or D.

\section{PREVENTION}

1. Smoking cessation continues to be recommended as a means to reduce breast cancer $(\mathrm{BC})$ risk (Grade C).

\section{SCREENING}

1. Bladder cancer screening, if undertaken, should be confined to high-risk patients (Grade C).

- Such screening cannot be recommended for the general population (Grade C).

" There was some discussion on this in the Q\&A. Overall evidence is low, but there are very small series that suggesting increased diagnosis of BC in high-risk populations, but no evidence that it correlates with different long-term outcomes.

2. Screening can consist of annual cytology and urinalysis (dipstick) (Grade C).

\section{EVALUATION}

1. Hematuria evaluation requires upper tract imaging (Grade B).

2. Urine cytology and cystoscopy should be used for gross hematuria or symptomatic hematuria or in patients with risk factors for urothelial carcinoma (Grade B).

3. Urine cytology or cystoscopy should be used for microscopic hematuria or in patients without risk factors for urothelial carcinoma (Grade B).

\section{Cystoscopy}

- White light cystoscopy is the gold-standard evaluation (Grade B).

- A bladder diagram should be used at the time of first cystoscopy prior to transurethral resection of bladder tumor (TURBT) to precisely locate tumor (Grade C).

" Photodynamic agents (i.e. hexaminolevulinate), may be used (Grade B).

" As an adjunct to white light cystoscopy for diagnosis of BC

" As an adjunct to TURBT for treatment of BC

" Narrow-band imaging may be used (Grade C)

" Not as useful as photodynamic agents

\section{Cytology (discussed further in Dr. Eva Compérat's presentation)}

- Voided cytology should be used for monitoring high-grade recurrence (Grade B).

" Voided cytology should be utilized to differentiate low- and high-grade tumors (Grade B).

- Bladder wash cytology (as opposed to voided cytology) may be considered for high-risk situations due to better diagnostic yield (Grade C). - but minimize manipulation (Level of Evidence 4)

\section{URINARY MARKERS}

- There was a separate chapter on urinary markers.

- However, in general, no recommendations (Grade D) for urinary markers for follow-up or diagnosis.

\section{IMAGING}

1. Imaging of the upper tracts is necessary in patients with hematuria (Grade B).

2. Computed tomography (CT) urography (triphasic CT) is the goldstandard test as part of initial staging and evaluation (Grade B).

" Other tests, including intravenous urography, noncontrast CT, ultrasound, and magnetic resonance urography are options (Grade C).

3. Imaging should be obtained before TURBT or more than 2 weeks post-TURBT (Grade C).

4. Metastatic staging workup should include chest x-ray (Grade B) and bone scan for symptomatic bone pain or elevated alkaline phosphatase (Grade B).

5. For patients on surveillance, a risk-adapted strategy is recommended, which will be listed in the final chapter (Level of Evidence 4-expert opinion).

\section{TURBT}

1. Prior to initial TURBT, a complete thorough cystoscopy with 30-degree and 70-degree scopes (or a 12-degree scope instead of the 30-degree type) (Grade C).

2. Plan best method of maximal tumor burden resection prior to initiating TURBT (Grade C).

3. Give patients appropriate prophylactic antibiotics (Grade B).

4. Three key principles during TURBT: (Grade C)

" Limit cautery artifact

" Ensure adequate depth of biopsy

- Proper handling of tissue for pathologic processing after removal

5. Complete resection should be attempted (ideally in 1 setting) in all patients except for those with diffuse carcinoma in situ (CIS) (Grade C). 


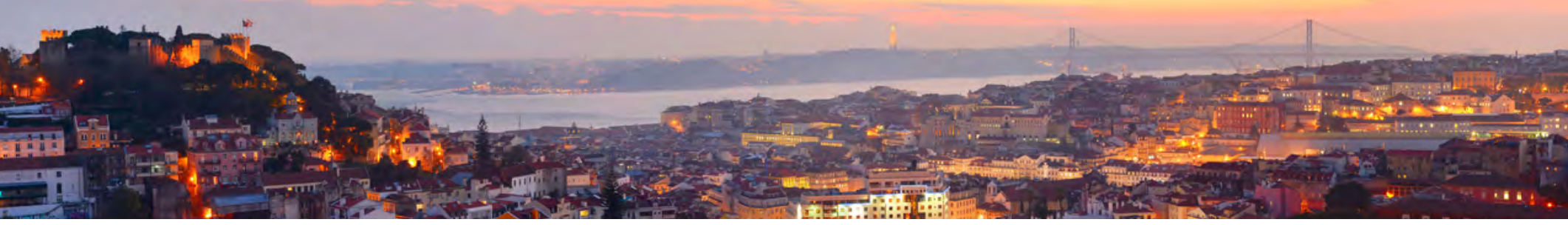

6. The following should be documented in each procedure note for TURBT:

" Shape, size, and location of tumor

" Papillary or sessile

- Suspected CIS in addition?

- Appearance at the base of tumor

" Visible muscle fibers or fat at completion of resection?

7. Separate specimen from the base should be sent when the tumor appears to be cT1+ (Grade C).

8. Use of cold-cup biopsy is recommended for small papillary tumors to limit cautery artifact (Grade C).

9. For tumors in diverticuli, aggressive resection should be avoided to reduce risk of perforation and spillage (Level IV).

10. If ureteral orifices are resected, cutting current should be used and functional imaging must be completed 3 to 6 weeks later (Grade C).

11. No specific recommendations regarding modality of resectionbipolar, monopolar, laser (Grade D).

12. Random biopsies:

- Not routinely recommended (Grade C)

- May be indicated in patients with:

" Positive cytology but negative white light cystoscopy

" Partial cystectomy candidates

13. Prostatic urethral biopsies

- Consider in patients with CIS or visible abnormalities in prostatic urothelium (Grade B).

- Not useful in counseling patients for neobladder (Grade C).

- Useful in counseling patients considering neoadjuvant chemotherapy by identifying T4 disease (Grade C).

14. Repeat TURBT

- Second TURBT should be done in all patients with high-grade T1 lesions regardless of muscle presence in first biopsy (Grade B).

- Second TURBT should be considered for some patients with high-grade pTa lesions (Grade C).

" Optimal timing is 4 to 6 weeks (Grade C).

PRESENTED BY: ASHISH M. KAMAT, MD, UNIVERSITY OF TEXAS MD ANDERSON CANCER CENTER, HOUSTON, TEXAS

WRITTEN BY: THENAPPAN CHANDRASEKAR, MD, CLINICAL FELLOW, UNIVERSITY OF TORONTO, TORONTO, ONTARIO, CANADA

\section{Joint Consultation on Bladder Cancer - Non-urothelial Cancer of the Urinary Bladder}

Dr. Badrinath Konety discussed the rare variants of bladder cancer, specifically targeting the cases where less than $1 \%$ of the specimen was urothelial. As can be imagined, there is little data available to make strong recommendations.

He reviewed each variant by histology as well as the major recommendations. Of note, more recent series have suggested that variants tend be diagnosed at later stages. But stage-matched, there is no evidence they do any worse than their urothelial carcinoma counterparts.

1) Squamous cell carcinoma (SCC)

" Bilharzial (predominantly in the Middle East, related to schistosomiasis infection)

" Non-bilharzial-risk factors include chronic catheter, infections, spinal cord injury, smoking

" Surgery remains the mainstay, even for non-muscle-invasive bladder cancer

" External-beam radiation therapy (XRT) is not effective, though this generated controversy. Chemo-XRT is so effect for other SCC in the body, why not for bladder. The discussion pointed out that these patients may not be candidates for chemo, hence the inability to treat as other sites.

- Locoregional failure remains high despite treatment

Non-bilharzial SCC

- Radical cystectomy (RC) with wide local excision for patients with localized SCC of the bladder (Level of evidence [LOE] 2, Grade B)

- Radiation reserved for palliation (LOE 3, Grade C)

- Chemotherapy can be offered for metastatic disease (LOE 4, Grade C)

Bilharzial SCC

" RC should be offered as primary therapy for localized disease (LOE 2, Grade B)

" Neoadjuvant XRT +/- chemotherapy may provide survival benefit following RC (LOE 3, Grade C)

2) Adenocarcinoma

- Urachal and non-urachal-managed slightly differently

- Will be negative for prostate-specific antigen, prostatic acid phosphatase, p63; positive for CK7, CK20, CDX2

" RC is the mainstay of therapy (LOE 3, Grade B); partial cystectomy with umbilectomy and lymph node dissection is only an option for urachal adenocarcinoma (LOE 2/3, Grade B)

- Adjuvant XRT and 5-Fluorouracil may help-no strong evidence (Level 4, Grade C) 
3) Neuroendocrine cancer/small-cell cancer

- Similar to lung small-cell cancer genotypically

- Primary therapy is cisplatin/etoposide followed by RC or XRT (LOE 2/3, Grade B)

- Carcinoid variant responds better to surgery first (more indolent)

4) Micropapillary variant

" Even non-muscle-invasive bladder cancer micropapillary is aggressive

" Percentage of micropapillary in the specimen is associated with outcomes

- Consider early RC for those with micropapillary variant

" Early data from MD Anderson Cancer Center suggest dosedense methotrexate, vinblastine, Adriamycin, and cisplatin be efficacious in this patient cohort, which is not yet incorporated into the data analysis

- There are more rare variants that warranted their own guideline statements, but because of their rarity, not much time was spent on discussing them. Full guidelines will flesh out all of the variants and their management.

PRESENTED BY: BADRINATH KONETY, MD, UNIVERSITY OF MINNESOTA HEALTH, MINNEAPOLIS, MINNESOTA

WRITTEN BY: THENAPPAN CHANDRASEKAR, MD, CLINICAL FELLOW, UNIVERSITY OF TORONTO, TORONTO, ONTARIO, CANADA

\section{Joint Consultation on Bladder Cancer - Pathology}

Dr. Eva Compérat noted that the major changes from the pathology chapter in the 2012 edition: far fewer pathologists are involved ( 9 now vs. 35 then); the chapter had significantly shortened; the chapter was much more clinically oriented. As such, there are fewer pathology-focused technical descriptions, with more of it now targeting the urologic clinician.

The major new elements that were incorporated into the chapter were the World Health Organization (WHO) 2016 grading scheme, the Paris 2015 Cytology discussion, and the International Collaboration on Cancer Reporting (ICCR) 2017 recommendations. The WHO 2016 scheme accounted for new staging elements, new histologic subgroups, diverticulum pathology, immunohistochemistry and molecular immunohistochemistry. The ICCR was an effort from all pathology organizations to create a standardized reporting method so the data are easily translatable and can be found on www.iccr-cancer.org.

At the end of the day, in this chapter, grading remained the most controversial aspect.
1. Distinction between low-grade Ta and low malignant potential lesion is minimal and does not seem to have much effect on outcomes.

2. For Ta and T1 lesions, reverting back to 1973 WHO substratification of high grade (WHO 2006). Grades 2 and 3 have been shown to have greater prognostic value than high grade alone, with molecular studies recently confirming distinct genetic populations with different outcomes.

- Indeed, patients with histologically normal tissues may have molecular changes that predispose them to more aggressive growth.

\section{T1 subdivision}

" Substaging T1 lesions has remained controversial.

" This is important for clinical management, but there is no consensus on method.

" Though WHO recommended substaging T1 for the first time, no recommendation on how to report are included.

- ICCR recommends millimeters of invasion and extent of invasion or pT1a/b

4. Diverticular tumors

" There cannot be pT2.

\section{HISTOLOGY}

When it comes to histology, there are numerous subtypes and distinct breast cancer histologies now. Dr. Badrinath Konety discussed some of the variants as well, noting that there have been some changes in the terminology:

1. Clear cell added.

2. Signet ring has been re-categorized as a diffuse/plasmacytoid.

When it comes to variant histology, Dr. Compérat deferred to Dr. Konety. She did note that there is severe underreporting of variant histology, and it is unclear whether they truly have any different outcomes. Pure visible hematuria seems to have poorer outcomes than mixed disease.

\section{CONCORDANCE OF REPORTING}

Dr. Compérat observed that previous studies have demonstrated very high concordance for patients with classic forms of the disease ( 90\%), but very unimpressive concordance among all histologies (kappa $=0.54)$.

\section{URINE CYTOLOGY AND THE PARIS SYSTEM (2015)}

Review of urine cytology terminology and standardization

" Atypical urothelial cells do not mean cancer!

- A helpful flow chart from the Paris system highlights the decision making. 
" With recurrence, radical cystectomy $(\mathrm{RC})$ + urethrectomy (LOE 3)

" Tis in prostatic ducts

" Limited data

" RC if extensive in ducts (LOE 3)

" Alternative if TUR of the prostate + BCG

" Prostatic stromal invasion-treat as MIBC

\section{Management of low-risk and intermediate-risk non-MIBC}

" No significant change from the 2012 guidelines

" Single dose instillation therapy recommended within 6 hours (mitomycin C, epirubicin, pirarubicin) if low risk

" If intermediate risk, ongoing instillations

" Intermediate risk-risk-adapted approach recommended, based on EORTC risk calculator

In-clinic fulguration is acceptable for patients with recurrent low-grade Ta with no prior history of high-risk disease of CIS, and negative cytology

" New-expectant management for low-grade Ta is acceptable (Grade B)

- Urine cytology must be followed and be negative

- A protocol must be established and followed

\section{Management of high-risk non-MIBC}

- Repeat TUR of bladder tumor guidelines-similar to what was presented by Dr. Kamat

" Patients with variant histology, lymphovascular invasion, or deeply invasive T1 may not be candidates for bladder-sparing therapies and should be considered for early cystectomy (LOE 3, Grade C)

- BCG recommendations are unchanged

" The wording of maintenance ("at least 1 year") therapy was debated by the group. It was not felt this wording was strong enough based on the studies that demonstrated benefit with 3 years' maintenance. This may be changed prior to publication

" BCG failure

- Relapsing

- Refractory: disease progression after 1 cycle induction or persistent/worsening after 2 cycles of induction (LOE 3, Grade B)

- Unresponsive: BCG refractory and BCG relapsing high risk within 6 months of last BCG exposure

" RC is the gold standard for treatment (LOE 3, Grade C)

" Salvage intavesical therapy only if refuse RC and clinical trials
" Brief discussion without strong recommendations for alternative therapy (hyperthermia, etc)

" Grade B recommendations for radiofrequency-induced chemohypothermia, electromotive mytomycin C if unfit or unwilling to undergo RC or if BCG not available

Full details will be published in the printed chapter.

PRESENTED BY: WASSIM KASSOUF, MD, MCGILL UNIVERSITY, MONTREAL, QUEBEC, CANADA

WRITTEN BY: THENAPPAN CHANDRASEKAR, MD, CLINICAL FELLOW, UNIVERSITY OF TORONTO, TORONTO, ONTARIO, CANADA

\section{Joint Consultation on Bladder Cancer - Systemic Therapy for Metastatic Urothelial Carcinoma}

Dr. Axel Merseburger, along with Dr. Cora Sternberg, co-chaired for this chapter. There has been much development in this space over the past 5 years, so he highlighted some of the key changes along the way. However, the final published chapter will have the most up-to-date recommendations.

There were 5 general sections for this chapter:

1. First-line treatments, doublet-therapy, and triplet-drug combination with cisplatin therapy

2. Cisplatin-ineligible patients

3. Second-line treatments/Salvage chemotherapy monotherapy/ combination therapy

4. Targeted agents and biomarker driven strategies

5. Immunotherapy of bladder cancer

\section{FIRST-LINE TREATMENTS, DOUBLET-THERAPY, AND TRIPLET- DRUG COMBINATION WITH CISPLATIN THERAPY}

In the 5-year period, there has been better patient selection and supportive care as well as earlier diagnosis and screening:

Dose-dense MVAC (methotrexate, vinblastine, Adriamycin, and cisplatin) vs. MVAC (2006 Sternberg). At 2 years, there was a $10 \%$ survival improvement with dose-dense MVAC

" Decreased the toxicity and increased the efficacy

" European Organisation for Research and Treatment of Cancer or EORTC randomized study confirmed these findings

- Level 1 evidence, Grade A recommendation

- Important to remember that cisplatin chemotherapy is still the standard-of-care first-line therapy 


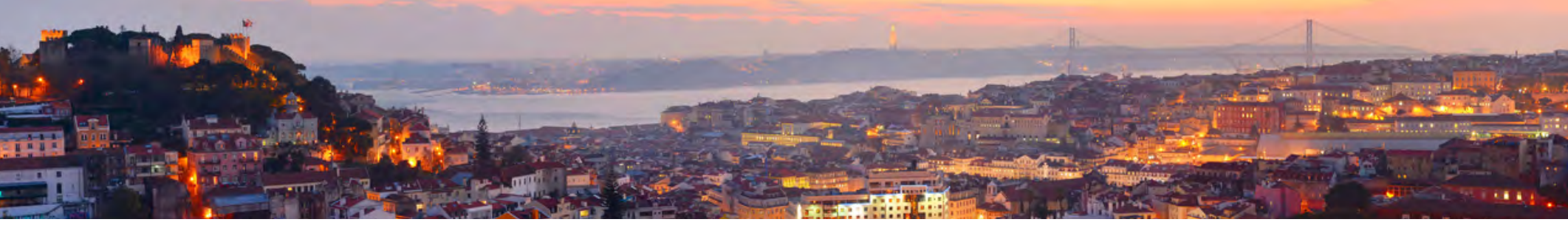

" Produced a 72\% objective response rate (ORR) in patients with metastatic urothelial cell cancer

- Doublet therapy (gemcitabine-cisplatin) is accepted as a standard-of-care first-line therapy as well

" Decreased rate of mucositis and neutropenia, but higher rate of thrombocytopenia

" Many have dropped the day 15 gemcitabine, resulting in a more tolerable 3-week course (Level 1b evidence)

\section{CISPLATIN-INELIGIBLE PATIENTS}

- Approximately one-half with muscle-invasive bladder cancer are ineligible for cisplatin therapy

- Carboplatin-based doublet therapy has traditionally filled this space, with ORR 36\% (Level of evidence [LOE] 2)

" More recently, immune checkpoint blockage has been introduced into this field

- Pembrolizumab (ORR 29\%) and atezolizumab (ORR 23\%) are now approved

" Level 2 evidence

" Median overall survival (OS) was 15.9 months (9.3 months for carboplatin-based doublets)

- Gemcitabine triplet-therapies

" Gemcitabine/cisplatin/paclitaxel-ORR 43\%

" Gemcitabine/paclitaxel/doxorubicin-ORR 56\%-Level 2 evidence

\section{SECOND-LINE TREATMENTS/SALVAGE CHEMOTHERAPY MONOTHERAPY/COMBINATION THERAPY}

- Vinflunine phase 3 trial monotherapy

- OS benefit compared with best supportive care, but was not an intention-to-treat analysis

" LOE 1b, Grade B

" Taxanes-limited activity

" LOE 2, Grade B

- Pemetrexed-limited activity

- Vascular endothelial growth factor receptor tyrosine kinase inhibitors - no role in second-line therapy

- More recently, the RANGE study (Petrylak et al, Lancet, Sept 2017) demonstrated prolonged progression-free survival (OS not available yet) with ramucirumab with docetaxel vs. docetaxel alone

" Promising, but not yet enough to make a recommendation

- At this time, no clear benefit for the use of combination therapy (LOE 2, Grade B)

\section{TARGETED AGENTS AND BIOMARKER-DRIVEN STRATEGIES}

Targeted agents were discussed extensively in earlier sessions, and the concept of precision medicine was already covered. As such, Dr. Merseburger did not spend much time on this topic. The group's guidelines were as follows:

" Enroll in biomarker-based clinical trials

- Biopsies at the time of progression or ctDNA profiling

" Level 2 evidence for:

- Sunitinib, ramucirumab with docetaxel, afatinib for patients with Her2/Her3 somatic alterations

- Enfortumab or multiple fibroblast growth factor receptor-3 inhibitors for individuals with fibroblast growth factor receptor-3-activating mutations

- Everolimus for patients with tuberous sclerosis 1/2 somatic mutations or inactivating mutations

\section{IMMUNOTHERAPY OF BLADDER CANCER}

These novel therapies are revolutionizing the field of systemic therapy for bladder cancer.

Five of these treatments have been approved by the U.S. Food and Drug Administration so far, and a few are utilized in phase 1 trials alone!

" Therefore, there is some room for improvement in the selection of patients who respond best

" Those with high mutational load and microsatellite instability seem to respond best

- However, as discussed previously, identifying good biomarkers has been difficult

Several are now even in trials for the adjuvant setting after radical cystectomy for high-risk muscle-invasive bladder cancer.

The full guidelines will expand further on the recommendations.

PRESENTED BY: AXEL MERSEBURGER, MD, UNIVERSITY HOSPITAL SCHLESWIGHOLSTEIN, LUBECK, GERMANY

WRITTEN BY: THENAPPAN CHANDRASEKAR, MD, CLINICAL FELLOW, UNIVERSITY OF TORONTO, TORONTO, ONTARIO, CANADA 


\section{Renal Tumor Anatomic Complexity: Clinical Implications for Urologists}

Dr. Robert Uzzo began by discussing tumor anatomic complexity, stating that urologists often intuitively know whether a renal mass will be an "easy" or a "hard" partial nephrectomy based on a cursory overview of axial imaging. Risk stratifying these masses in a standardized way, however, has been difficult, he observed.

Tumor complexity scoring helps quantify the degree of anatomic difficulty of surgical intervention. It is important to note that while not every tumor is the same, though, not every patient is the same either. Tumor management should always take into account patient factors as well.

By quantifying degree of complexity, this type of management can:

- Help inform case selection

" Predict ischemia

- Anticipate complications

- Predict active surveillance

- Possibly foretell pathology

As such, tumor management has now been incorporated into American Urological Association guidelines as part of Evaluation \& Management, Patient Counseling, and Treatment Decision Making.

Next, Dr. Uzzo focused specifically on the Nephrometry score, a geometry-based scoring system. It is a points-oriented system that revolves around size, endophytic/exophytic nature, nearness to collecting system or sinus, anterior/posterior, and location relative to polar lines. This is also known as theR.E.N.A.L. system, which is the acronym for its key components. The summed score from 4 to 12 can help group renal masses into low (4-6), medium (7-9), or high-risk (10-12) categories.

Beyond parenchymal complexity, though, additional features need to be considered: contact surface area, pelvic anatomy, and vascular anatomy. Contact surface area determines how much normal parenchymata are affected in addition to surface area that has been correlated with glomerular filtration rate change and blood loss.

Independently, there are additional methods to grade complexity as well as measures of hilar complexity. There are also other wellestablished complexity measuring tools, including Preoperative Aspects and Dimensions Used for Anatomic Classification or PADUA (Eur Urol. 2009), centrality index or C-index (J Urol. 2010), and arterial-based complexity or ABC score (Eur Urol. 2014). However, all of them ultimately have been correlated:

1. Complications post-nephron-sparing surgery that are specifically correlated with increased Clavien-Dindo classifications

\section{Complications postablation}

3. Warm ischemia time

4. Leak
5. Operative approach, more likely to pursue the open type for highcomplexity lesions

6. Hemorrhage

7. Pathology

8. Survival

9. Choice of treatment, including decisions to biopsy and to pursue active surveillance

10. Renal failure

\section{Operative time}

Higher-volume centers are more likely to perform nephron-sparing surgery in those with intermediate-risk or high-risk Nephrometry scores due to comfort.

He also highlighted the impact of fat type on surgical outcomes. Anecdotally, every surgeon knows that there is "good fat" and "bad fat." Older patients and men have more perinephric fat, often referred to as "bad fat." Fat thickness at renal vein, fat stranding, and other measures have been introduced (Mayo Adhesive Probability score) to help predict this factor prior to surgery.

The urinary collecting system is important to evaluate as well. Collecting system anatomy can assist in predicting urine leak. Small intrarenal renal pelvis may foretell higher urine leaks that are traceable to higher intrarenal pelvic pressures compared with extrarenal dilated renal pelvis.

In conclusion, Dr. Uzzo observed that there is much work that can be done in this field to help better counsel patients, prepare for surgery, and predict outcomes.

PRESENTED BY ROBERT UZZO, MD, FOX CHASE CANCER CENTER, PHILADELPHIA, PENNSYLVANIA

WRITTEN BY: THENAPPAN CHANDRASEKAR, MD, CLINICAL FELLOW, UNIVERSITY OF TORONTO, TORONTO, ONTARIO, CANADA

\section{New Therapy for Advanced Renal Cell Carcinoma (RCC)}

Dr. W. Marston Linehan presented information targeting the treatment of advanced RCC, specifically barriers and new opportunities, and focusing on major principles that include the personalization of therapies rather than specifics.

At this point in time, we are up to 17 different RCC subtypes, and this will likely expand. In addition, there are new possibilities in the field that require further exploration. While well-focused therapies have been approved for over a decade, the introduction of the immune checkpoint inhibitors has reinvigorated this area of medicine. Having been present for the initial experience with immune therapy (interferon-alpha, interleukin-2), Dr. Linehan felt that the current immune checkpoint inhibitors show much promise, suggesting that 


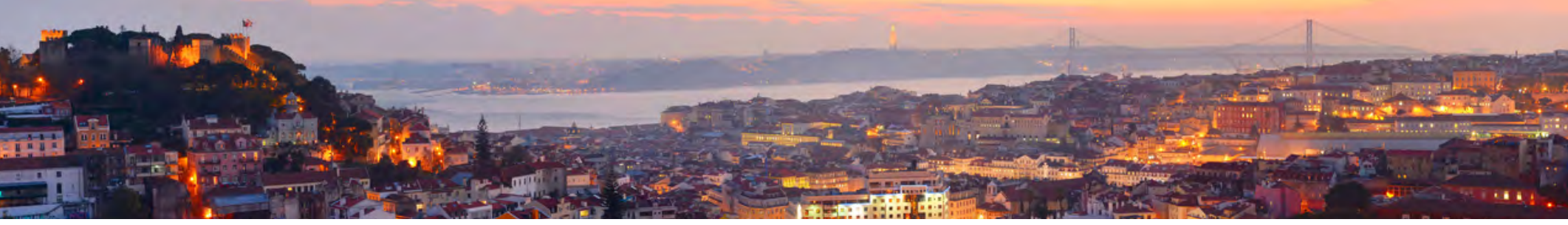

his audience pay attention to the development of chimeric antigen reception therapy or CAR-T, which has yet to demonstrate success in solid malignancies. But when CAR-T does begin to show potential, it may again drastically change the landscape of opportunities. Lastly, the possibility of combination therapies-immune checkpoint therapies with each other, with targeted therapies, and even with other agents-may yield greater results than any monotherapy does.

Dr. Linehan indicated that there are three main histologies of RCC to highlight some of the progress made, putting the spotlight on clear cell RCC, papillary type I RCC, and papillary type II RCC. While much discussion was on anecdotal evidence or molecular pathways, there were some important take-home messages: Intratumoral heterogeneity has become critically important, and RCC is understood to have significant heterogeneity, even within the primary lesion. Better characterization of the primary tumor and metastases can help guide more pinpoint therapy.

He opined that there will be significant advancements in the stratification and management of patients with RCC in the next several years. However, international collaboration among centers of excellence is reportedly the key to success.

PRESENTED BY: W. MARSTON LINEHAN, MD, NATIONAL CANCER INSTITUTE, CENTER FOR CANCER RESEARCH, BETHESDA, MARYLAND

WRITTEN BY: THENAPPAN CHANDRASEKAR, MD, CLINICAL FELLOW, UNIVERSITY OF TORONTO, TORONTO, ONTARIO, CANADA

\section{Management of Complex Renal Masses: Risk Benefit Trade-off of Partial vs. Radical Nephrectomy}

Dr. Alessandro Volpe presented a lecture on the management of complex renal masses, specifically weighing the risk/benefit ratios of partial nephrectomy (PNx) and radical nephrectomy (RNx).

He reviewed the major urologic-guideline recommendations, with surgery remaining the mainstay of therapy for localized kidney cancer, particularly T1 and T2 diseases. There is strong evidence suggesting that PNx is preferred over RNx for patients with T1 lesions. PNx should be prioritized for those with T1 lesions as well as for individuals with solitary kidneys, bilateral masses, known familial renal cell carcinoma, preexisting chronic kidney disease, and proteinuria. This type of nephrectomy should also be considered for patients who are young or have comorbidities (hypertension, diabetes) that may affect renal function in the future.

- However, the evidence to support this is quite low and primarily based on retrospective cohort studies

" None of the studies stratifies patients by surgical complexity

- In terms of incidence, though, the incidence of PNx has been steadily rising, while the rate of RNx has been decreasing

\section{FACTORS THAT SHOULD BE ACCOUNTED FOR IN THE DECISION-MAKING PROCESS:}

1. Tumor factors

- Tumor complexity-Nephrometry scores, PADUA (Preoperative Aspects and Dimensions Used for Anatomic Classification) scores, C-index

- Histology and grade, biopsy pathology

" Tumor growth pattern and kinetics

- Tumor focality

- Tumor size

2. Patient factors

- Baseline renal function

- Comorbidities

\section{Surgical factors}

- Robotic surgery-advent has allowed for easier/faster tumor excision, expansion of the indications for $\mathrm{PNx}$, shorter learning curve than laparoscopic PNx; but only intermediate follow-up data are available and expensive

\section{EVIDENCE SUPPORTING PNX:}

" Based mainly on retrospective series

- Oncologic outcomes have been shown to be the same between the 2 surgical options

- Only 1 randomized study in this space-European Organisation for Research and Treatment of Cancer or EORTC study (Van Poppel et al)

- The estimated risk of death from renal cell carcinoma following nephron-sparing surgery (NSS) was not significantly higher than RNx (hazard ratio 2.06, confidence interval 0.62-6.81, $P=.23$ )wide range traceable to small number of cancer deaths

- In cT1 tumors up to $5 \mathrm{~cm}$ in size

- NSS spares renal function-well-established

- Long-term functional outcomes of EORTC study, while estimated glomerular filtration rate is, on average, lower for patients undergoing RNx compared with NSS, neither group experiences a continued decline over time

- Lower estimated glomerular filtration rate (particularly due to medical causes) is associated with cardiovascular events, hospitalization, and higher rates of death

- In studies accounting for confounding variables such as diabetes and heart disease, patients with RNx still had higher rates of cardiovascular events and all-cause mortality

- However, this benefit was not seen in the Van Poppel randomized, controlled trial (the only Level 1 evidence available)

- May be because of bias of retrospective analysis and confirmed in a Surveillance, Epidemiology, and End Results or SEER study, 
in which patients undergoing NSS had better overall survival than patients not undergoing surgery at all!

- Ultimately, NSS likely preserves renal function, but does so without any evidence of overall survival benefit

- Propensity-matched analysis suggests some overall-survival benefit for patients younger than 65 years of age

" These benefits have to be balanced, though, against the risk of positive surgical margins and that of leaving disease behind

- In general, positive surgical margins may not equate to worse oncologic outcomes; in high-risk patients with positive surgical margins, rate of recurrence can be quite high (Shah et al)

\section{CONCLUSIONS:}

1. NSS is the gold-standard treatment for localized pT1 tumors

2. It has comparable oncologic outcomes to RNx

3. This form of surgery leads to better renal function sparing than RNx does

4. It avoids progression to severe chronic kidney disease in patients with solitary kidneys or baseline-poor chronic kidney failure

5. This surgery may decrease the risk of cardiovascular deaths and all-cause mortality in selected patients.

PRESENTED BY: ALESSANDRO VOLPE, MD, UNIVERSITY OF EASTERN PIEDMONT, NOVARA, ITALY

WRITTEN BY: THENAPPAN CHANDRASEKAR, MD, CLINICAL FELLOW, UNIVERSITY OF TORONTO, TORONTO, ONTARIO, CANADA

\section{The Unmet Need in Locally Advanced Renal Cell Carcinoma (RCC) Treatment: Game Changers?}

Three well-respected urologic oncologists were asked to speak about the single most important observation of the recent past, choosing the areas that they felt represented the most exciting discoveries.

In one of these lectures, Dr. Peter Mulders discussed the Sunitinib Trial in Adjuvant Renal Cancer or S-TRAC, ${ }^{1}$ The New England Journal of Medicine paper in which sunitinib was assessed in the adjuvant setting for patients with high-risk localized RCC treated with nephrectomy.

Individuals who undergo major extirpative surgery for high-grade localized or locally advanced RCC have a high risk of recurrence and outcomes similar to good-risk metastatic RCC, but there are no good predictors as to who develops those metastases. While there are numerous nomograms to risk-stratify patients based on clinical characteristics (the University of California Los Angeles Integrated Staging System, etc.), these were used in the major adjuvant trials and have not demonstrated enough discriminatory value to show benefit of adjuvant therapy.
Dr. Mulders briefly reviewed the history of adjuvant therapy trials for RCC, starting with those utilizing classic immunotherapy followed by the use of targeted therapy. He made some important points regarding the mode of action of that particular treatment, specifically as an angiogenesis inhibitor. In principle, would this therapy work on micrometastatic disease?

Getting back to the S-TRAC Study, it was the first positive trial for adjuvant therapy in this disease space. However, the ASSURE (Adjuvant Sorafenib or Sunitinib Unfavorable Renal Carcinoma) Trial demonstrated no specific benefit in this same population. ${ }^{2}$ There are more trials reporting soon or ongoing, but the pazopanib adjuvant study also proved negative.

At this time, there is no recommended adjuvant therapy. However, there is indeed an unmet need for this type of therapy. Novel treatments such as immune checkpoint blockage may provide benefit that has not been convincingly seen with targeted therapy.

PRESENTED BY: PETER MULDERS, MD, RADBOUD UNIVERSITY MEDICAL CENTER, NIJEGEN, THE NETHERLANDS

WRITTEN BY: THENAPPAN CHANDRASEKAR, MD, CLINICAL FELLOW, UNIVERSITY OF TORONTO, TORONTO, ONTARIO, CANADA

\section{REFERENCES}

1. Ravaud A, Motzer RJ, Pandha HS, et al; and S-TRAC Investigators. Adjuvant sunitinib in high-risk renal-cell carcinoma after nephrectomy. N Engl J Med. 2016;375(23):2246-2254.

2. Haas NB, Manola J, Uzzo RG, et al. Adjuvant sunitinib or sorafenib for high-risk, non-metastatic renal-cell carcinoma (ECOG-ACRIN E2805): a double-blind, placebo-controlled, randomised, phase 3 trial. Lancet. 2016;387(10032):2008-2016.

\section{The Synergic Effect of Metformin and Everolimus in Renal Cell Carcinoma (RCC)}

Dr. Young Eun Yoon discussed a study that investigated the antitumor effects of metformin teamed with everolimus on RCC cell lines.

The water-soluble tetrazolium salt cell viability assay and colonyformation assays were performed to investigate the effects of metformin, everolimus, and their combination on normal kidney epithelial cells (hexokinase-2, LLC-PK1) and RCC (Cakil, Caki2) cell growth. Signaling molecules involved in mammalian target of rapamycin (mTOR) signaling was analyzed by immunoblot analysis of various proteins, including mTOR, AMP-activated protein kinase, 4E-binding protein 1, and p70S6K.

This particular tetrazolium salt cell viability assay showed that both metformin and everolimus reduced cell viability of normal kidney cells and renal cancer cells in a dose-dependent manner. Metformin combined with everolimus had a synergistic inhibitory effect in a dose-dependent manner. In Caki-2 cell, metformin and everolimus together effectively inhibited colony formation. In addition, this blend inhibited mTOR down signaling molecules, AMP-activated protein kinase, 4E-binding protein 1, and p70S6K in Caki-2 cell. 


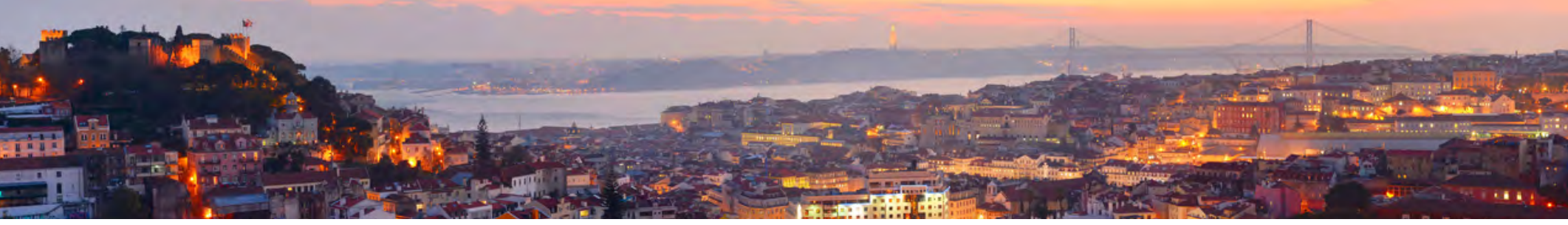

The study demonstrated the synergic antitumor effects between metformin and everolimus, which could potentially be a prospective therapeutic strategy to achieve potent antitumor effects on RCC.

PRESENTED BY: YOUNG EUN YOON, MD, YONSEI UNIVERSITY HOSPITAL, SEOUL, SOUTH KOREA

WRITTEN BY: HANAN GOLDBERG, MD, UROLOGIC ONCOLOGY FELLOW (SOCIETY OF UROLOGIC ONCOLOGY), UNIVERSITY OF TORONTO, TORONTO, ONTARIO, CANADA

\section{Variation in Surgical Quality Affects Outcome of Renal Cell Carcinoma (RCC) Treatment}

Dr. Antonio Finelli covered surgical quality control in the setting of nonmetastatic RCC, specifically focusing on data-driven quality-ofcare outcomes. While there are many studies expanding the horizon of what can be done, it is a must to continue assessing what is already being done and whether or not it can be improved.

He began by reviewing some of his own group's assessments of quality indicators within the Canadian healthcare system, along with the deficiencies they found. Specifically, they included low-volume surgeons at low-volume centers with high levels of complications, a lack of adherence to established guidelines, and surgeon learning curves that affected quality.

Dr. Finelli indicated that this can be a difficult topic to broach and is often not well-received by surgeons. But, he added, "understanding our limitations is an important step toward improving the field."

\section{VOLUME-OUTCOME RELATIONSHIPS IN THE TREATMENT OF RCC}

As with other malignancies, volume of surgery is associated with oncologic, functional, and perioperative outcomes.

" In-hospital mortality was more common in the practices of surgeons with low levels of performing such operations

- High-volume surgeons were more likely to do a nephronsparing surgery, have fewer in-hospital complications, and produce a lower in-hospital mortality rate

Establishing Quality Indicators (QIs)-to improve on the above findings, a Ql is needed. However, what is the right QI? How do we measure quality? What do we change based on the results?

" Donabedian model involves 3 different Qls-structure QIs, process Qls, and outcomes Qls-to help improve quality

Dr. Finelli then reviewed his work with RCC Qls in the Canadian healthcare setting. In a multiple-specialty working group, he and his colleagues were able to identify 23 Qls along the entire spectrum of RCC diagnosis, staging, treatment, and survival outcomes. This was based on data and expert opinion.

What makes a good QI?

- Valid

$$
\begin{aligned}
& \text { " Reliable } \\
& \text { " Feasible } \\
& \text { " Usable }
\end{aligned}
$$

The QI also needs to have inter-hospital variance so it can actually discriminate performance. Only if variance exists is there room for improvement!

The goal is to identify low-quality outliers, though all of those involved should continue to try for improvement!

Case-mix adjustment (accounting for case complexity) is important as case mix can affect quality measures.

Dr. Finelli's first attempt at benchmarking for RCC was to utilize the National Cancer Database (NCDB) to gauge hospital-level quality performance for RCC

" Qls (Case-mlx adjusted)

- Partial Nephrectomy Proportion (T1a)

- Minimally Invasive Proportion (T1-2)

- Positive margin rate (T1)

- Length of stay (T1-4)

" Re-admission rate (T1-4)

" While not perfect, Qls are well-suited for their intended purpose

- Validated in the NCDB first to ensure variations

- Composite scores allow for better stratification of patients, narrowing down those that are high outliers or low outliers on all QIs

" Learn from the high outliers

" Help the low outliers

- Composite score correlated with mortality and other adverse events helps indicate validity

Once created within the NCDB external database, they went on to assess Ontario hospitals with more granular data, which are pending.

\section{TAKE-HOME MESSAGES:}

1. Quality is far more than just surgical care and volume-outcomes relationships

2. Ideally, quality should also reflect nonsurgical management as well.

PRESENTED BY: ANTONIO FINELLI, MD, CANCER CLINICAL RESEARCH UNIT, PRINCESS MARGARET CANCER CENTRE, TORONTO, ONTARIO, CANADA

WRITTEN BY: THENAPPAN CHANDRASEKAR, MD, CLINICAL FELLOW, UNIVERSITY OF TORONTO, TORONTO, ONTARIO, CANADA 